Journal of Economic,

Administrative and Legal Sciences

Volume (6), Issue (3) : 30 Jan 2022

P: 102 - 125

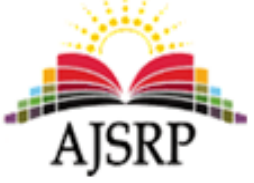

ISSN: 2522-3372
مجلة العلوم الاقتصيادية

والإدارية والقانونية

المجلد (6)، العدد (3) : 30 يناير 2022 م

ص: 102 - 125

\title{
The impact of strategic intelligence on crisis management in light of the spread of the Corona pandemic by applying it to the Saudi banking sector in the Asir region
}

\author{
Abdurrahman Ali Farraj Al-Asmari \\ College Business || King Khalid University || KSA
}

\begin{abstract}
There is no doubt that the Corona pandemic that struck the world had direct and indirect effects on all areas of our life.

Finance and economy, represented in the banking sector, was no exception to this.

To know the effects, this study aimed specifically at studying the impact of strategic intelligence on the management of crises in the banking sector in the Kingdom of Saudi Arabia, specifically in the Asir region (the cities of Abha and Khamis Mushait), and knowing the extent to which the employees of those banks are aware of the concept of strategic intelligence in achieving crisis management.

The descriptive correlative approach was applied after designing a questionnaire that includes three sections, including the personal data section, the strategic intelligence section, and the crisis management section, and it was distributed to 154 samples, They were randomly selected from over 2000 employees in the area.

As a result of the field survey, it showed that some indicators and dimensions were applied at high rates, such as foresight, vision, thinking, motivation, partnership, and the crisis management perspicacity,

in addition to the availability of a high application of strategic intelligence.

This study recommended the need to develop future forward-looking plans to reach a better distinction in the face of future crises, with the relentless pursuit by the management of banks to reach a better mental image of customers and to follow partnership in achieving a higher and more comprehensive development by collecting the elements of that image and then placing it under the brainstorming mechanism to be Analysis and detection of internal factors within a high capacity.
\end{abstract}

Keywords: Strategic intelligence, crisis management, corona.

$$
\begin{aligned}
& \text { أثر الذكاء الاستراتيجي على إدارة الأزمات في ظل انتشار جائحة كورونا } \\
& \text { بالتطبيق على القطاع المصرفي السعودي بمنطقة عسير } \\
& \text { عبدالرحمن علي فراج الأسمري } \\
& \text { كلية الأعمال || جامعة الملك خالد || المملكة العربية السعودية }
\end{aligned}
$$

المستخلص: لا شك أن جائحة كورونا التي ضربت العالم البشري كانت ذات آثار مباشرة وأخرى غير مباشرة على كافة مجالات الحياة

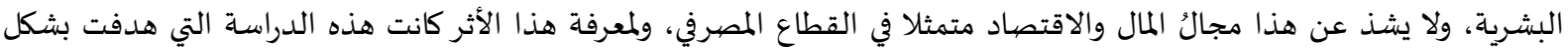

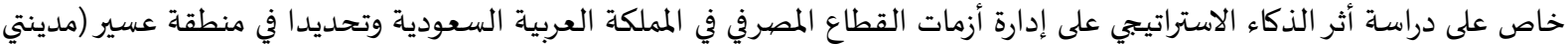

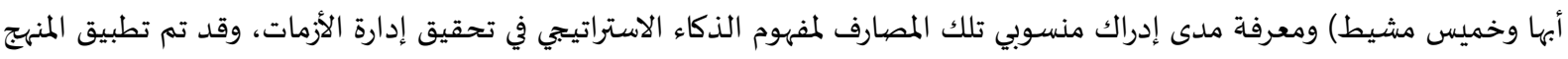


الوصفي الارتباطي بعد تصميم استبيان يتضمن ثلاثة أقسام تشمل قسم البيانات الشخصية وقسم الذكاء الاستراتيجي وقسم إدارة

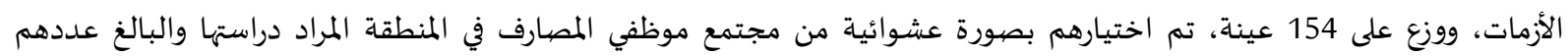

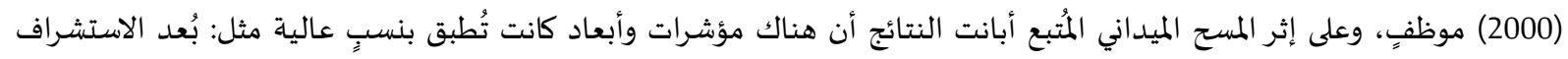

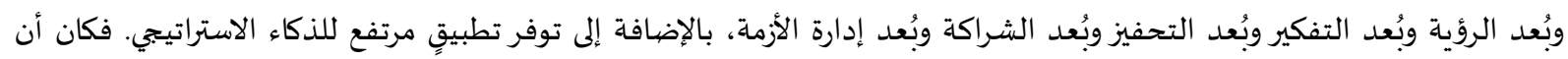

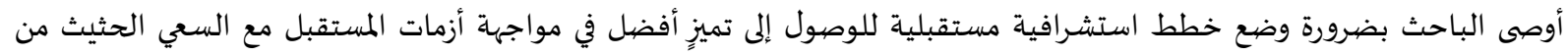

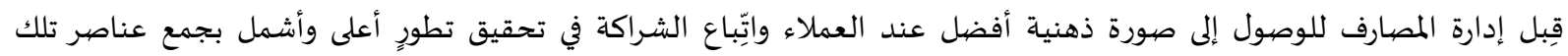

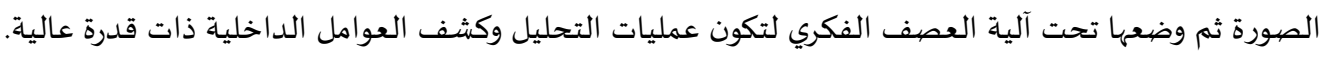

الكلمات المفتاحية: الذكاء الاستراتيجي، إدارة الأزمات، جائحة كورونا

مقدمة.

في ظل التغيرات والتحولات يعيش العالم على العموم وعالم الأعمال على الخصوص حاليا، تطورات كثيرة

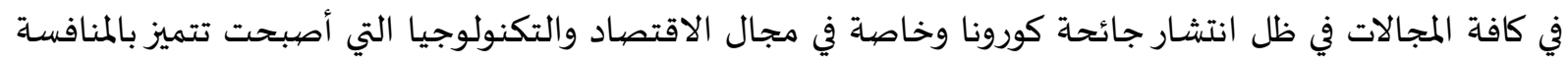

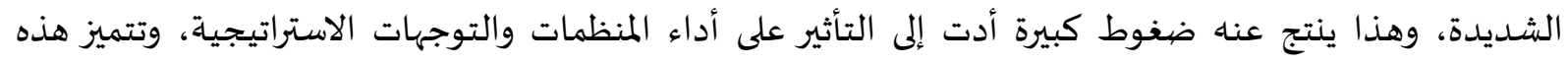

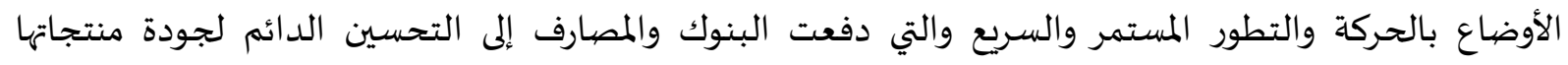

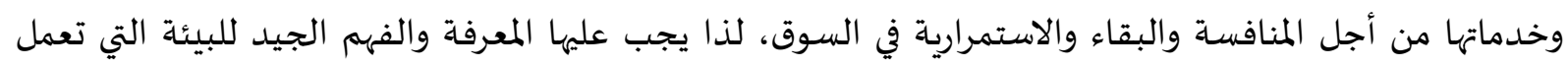

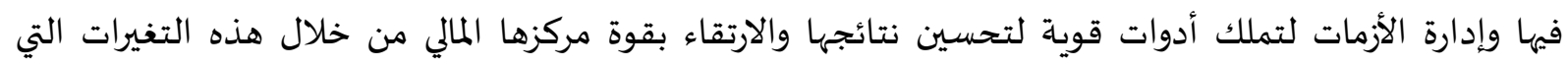

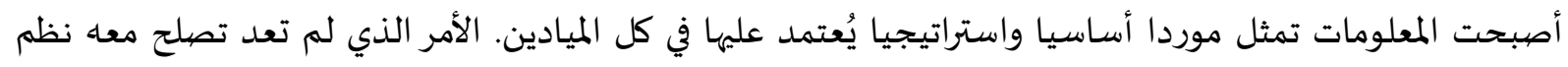

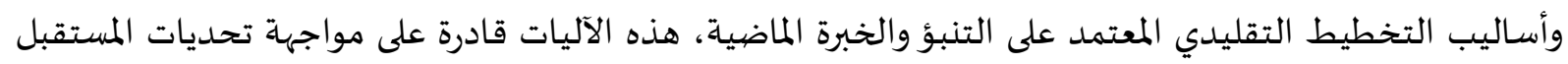

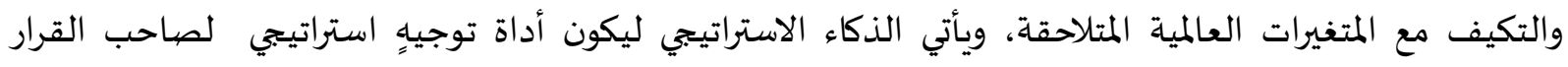

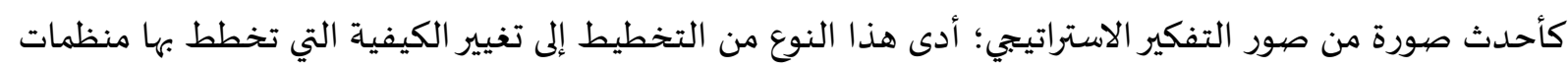

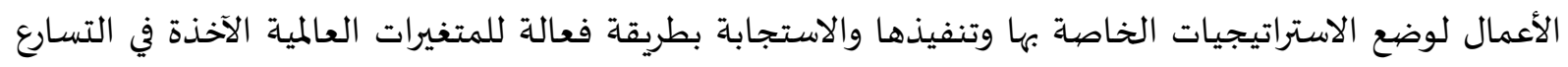

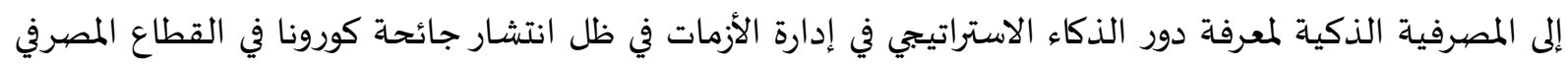
بمنطقة عسير. يرتبط الذكاء الاستراتيجي بنوع مميز من القدرات العقلية التي يحتاجها المدير والمفكر الاستراتيجي، والتي تتيح

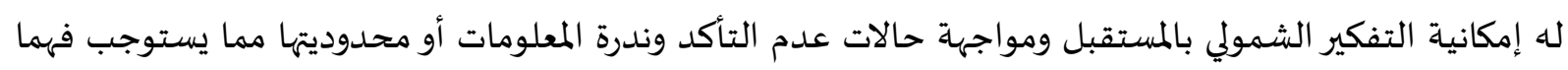

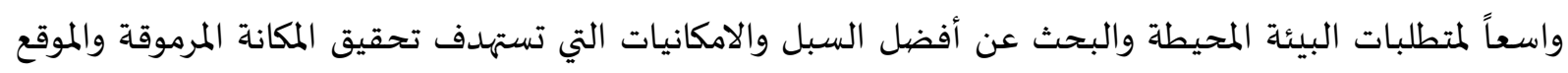

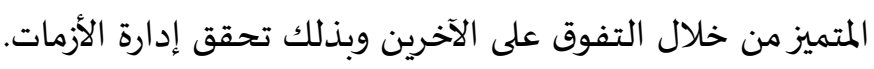

مشكلة الدراسة: في البدء نود أن نطرح أسئلة حتى نتبين طبيعة الواقع المصرفي وقدرته على مواجهة الأزمات الطارئة

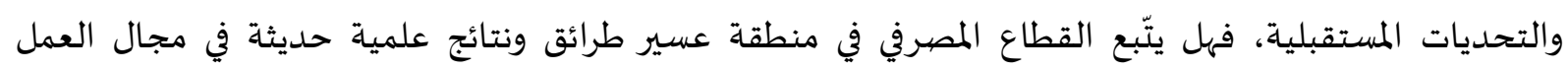

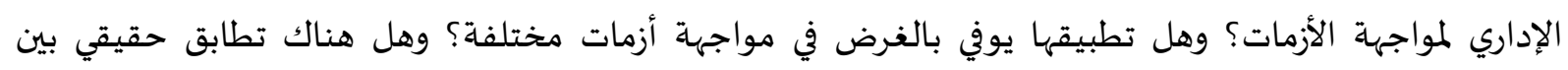

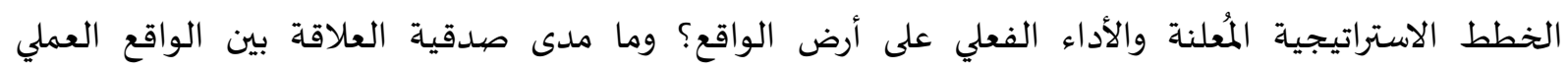

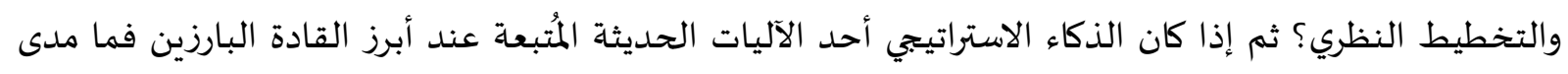

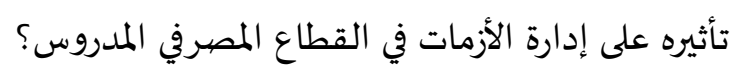




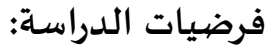

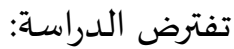

$$
\begin{aligned}
& \text { 1. يوجد تطبيق للذكاء الاستراتيجي في القطاع المصرفي بمنطقة عسير بدرجة متوسطة. } \\
& \text { 2. يوجد اهتمام بالقطاع المصرفي لإدارة الأزمات بدرجة متوسطة. }
\end{aligned}
$$

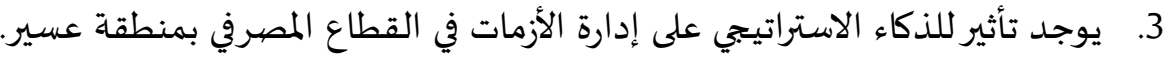

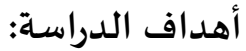

1. معرفة أثر تطبيق الذكاء الاستراتيجي والعناصر المكونة له في القطاع المصرفي بمنطقة عسير.

2. معرفة مدى إدراك منسوبي المصارف لمفهوم الذكاء الاستراتيجي في تحقيق إدارة الأزمات.

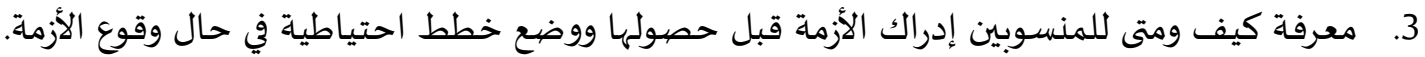

أهمية الدراسة:

تنبع أهمية هذه الدراسة من منهجية نتائجها العملية الإحصائية، فبعيدا عن التوصيف النظري والفكر

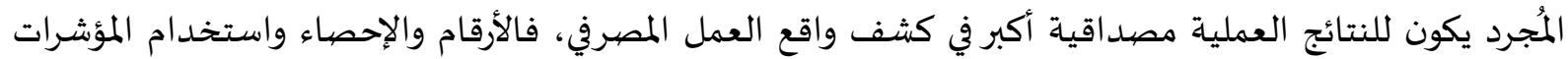

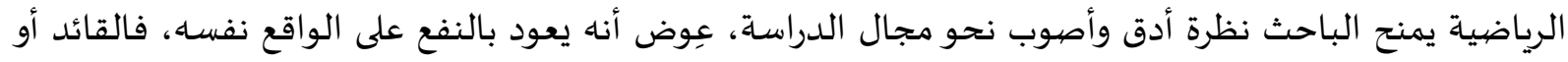
رائد الأعمال ينتفع من النتائج البحثية التطبيقية في وضع الخطط البديلة والاستراتيجيات البناءة.

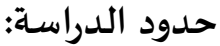

الحدود الموضوعياة: أثر الذكاء الاستراتيجي على إدارة الأزمات في ظل انتشار جائحة كورونا

الحدود البشرية: الأفراد العاملين في المصارف السعودية في مدينتي خميس مشيط وأبها. الحدود المكانية: المصهارف العاملة والمرخصية من البنك المركزي في مدينتي أبها وخميس مشيط مشيط. الحدود الزمانية: خلال الفترة الزمنية؛ من شهر يناير 2021 إلى مارس 2021.

\section{مصطلحات الدراسـة: - ت}

- الذكاء الاستراتيجي: يُعبر باه عن تلك العمليات الذهنية التي تبني نتائجها العملية وترسم خططها المستقبلية على

$$
\text { معلومات وبيانات واقعها الحالي وتغيراته المتوقعة. }
$$

- إدارة الأزمة: طريقة عملية تحقق توازنا مطلوبا بين واقع طبيعي سابق ولحظة حرجة تهدد مصير المنظمة للوصول إلى قرارات صحيحة.

$$
\text { 2- 2 - الدراسات السـابقة. }
$$

- دراسة بغدادي فيصل، 2014؛ هدفت الدراسة التعرف على دور القيادة في إدارة الأزمات في المنظمة، وتم استخدام المنهج الوصفي، وذلك لشدة ارتباطه بدراسة المشكلات المتعلقة بالمجالات الإنسانية. اعتمد عليه الباحث في جمع المعلومات عن الموضوع محل الدراسة من خلال الوقوف عند متغيراته وتحديد مفاهيماه. والمنهج التاريخي يمدنا بالجانب الوصفي في دراسة الظواهر في إطارها الزماني والتطورات التي لحقت بها، والقصد من

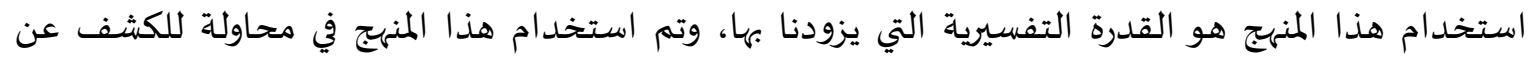

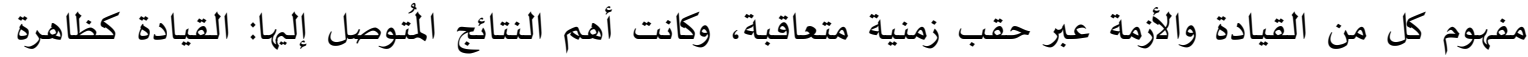




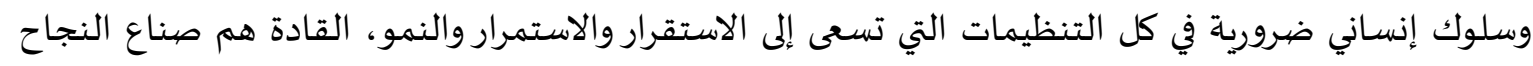
داخل المنظمات، وأههم الحلقة الأساسية ضمن عناصر القيادة الإدارية داخل المنظمة، أن تعقد الأزمات وات وتواليها

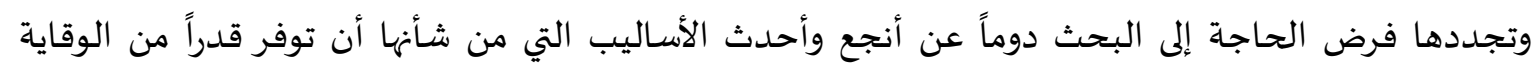

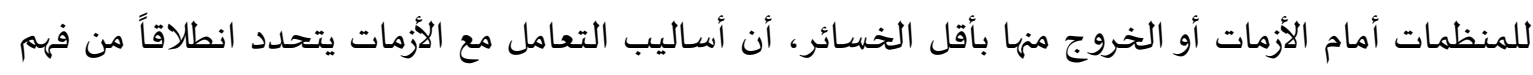

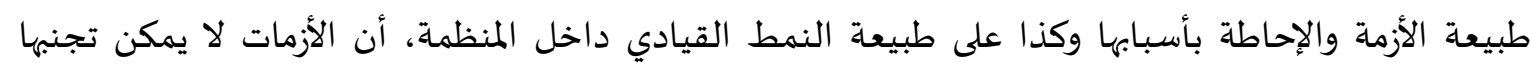

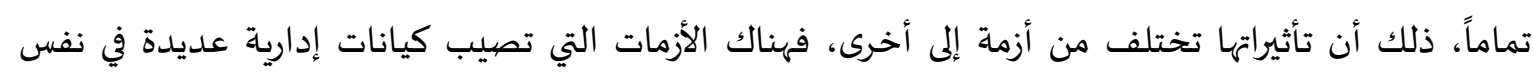

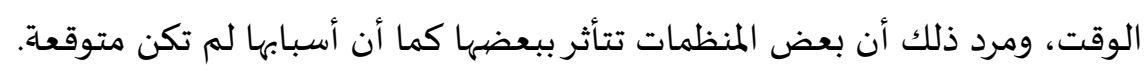

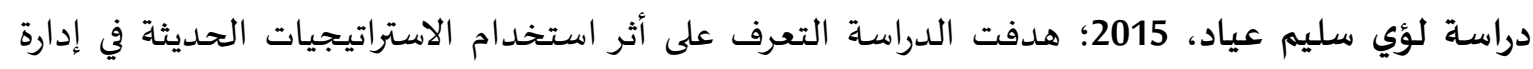

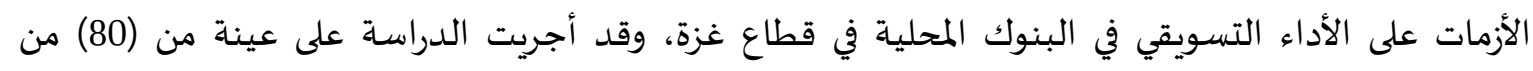

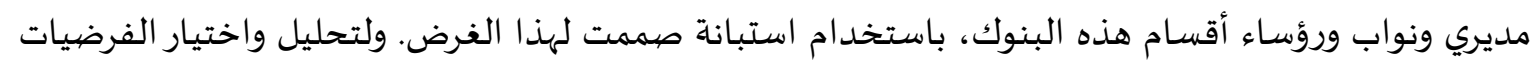

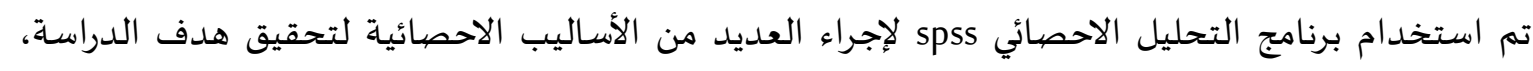

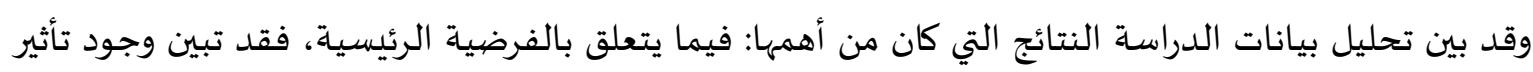

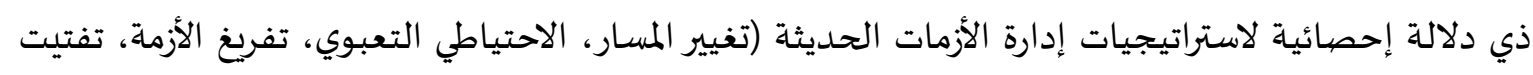

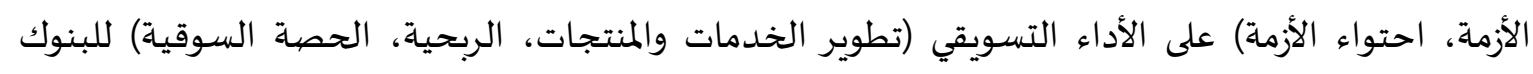

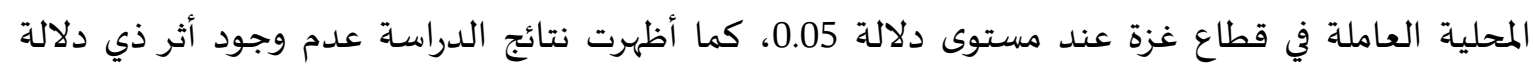

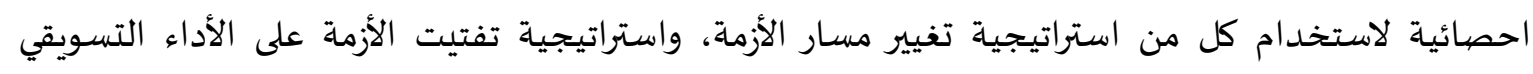

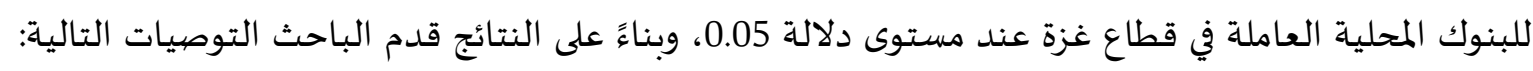

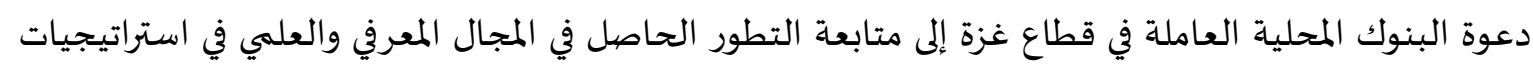

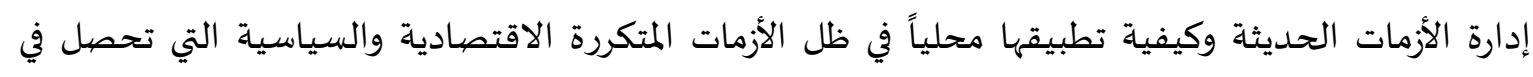

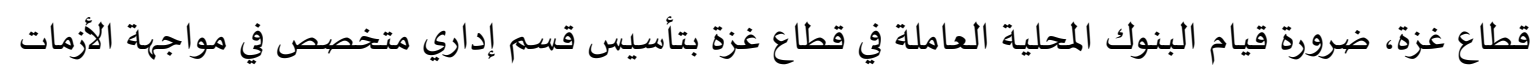
وكيفية استخدام استراتيجيات الأزمات الحديثة بكفاءة وفاعلية.

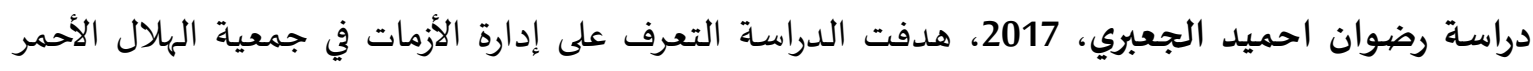

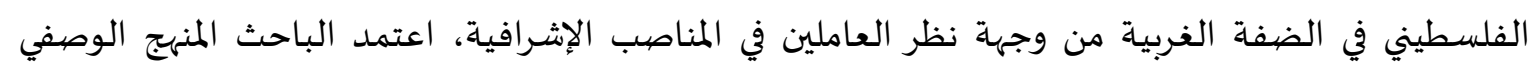

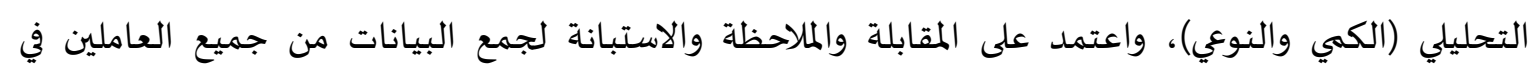

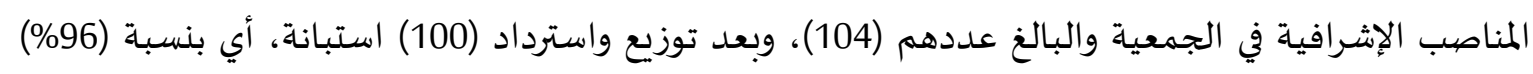

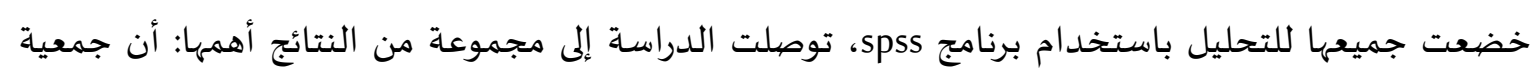

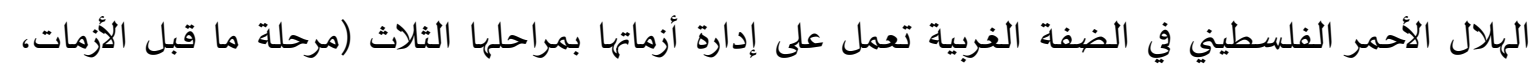

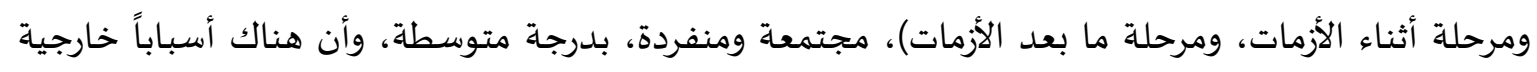

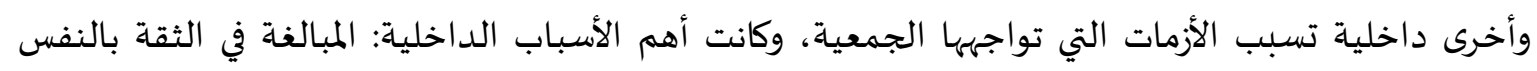

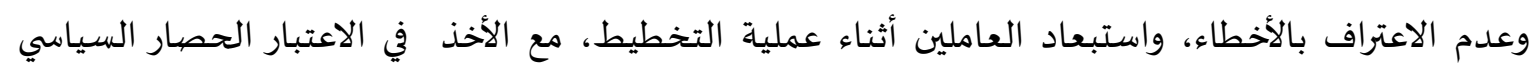

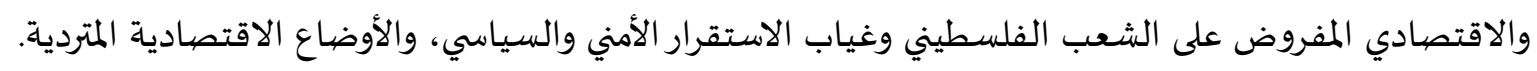

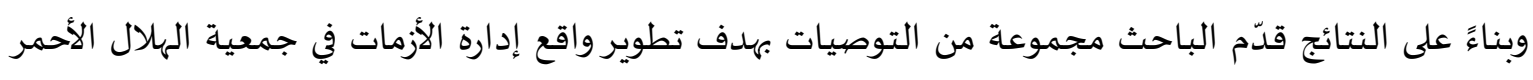

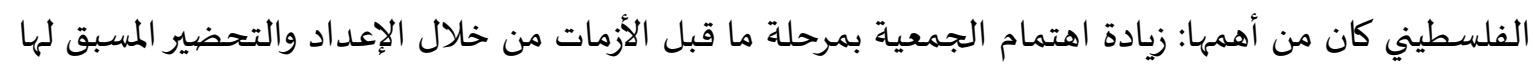

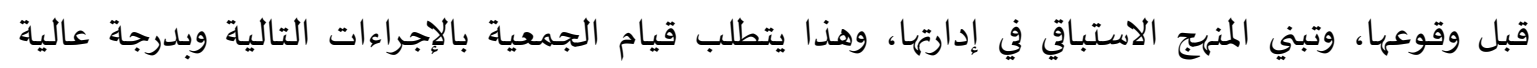


وكافية: تشكيل إدارة دائمة ومتخصصية لإدارة الأزمات في الجمعية "إدارة الأزمات"، لتكون كياناً مستمراً وثابتاً

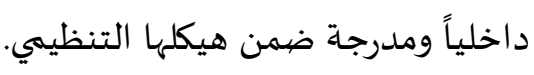
دراسة يونس إبراهيم جعفر، 2017. هدفت الدراسة معرفة أثر التخطيط الاستراتيجي في إدارة الأزمات،

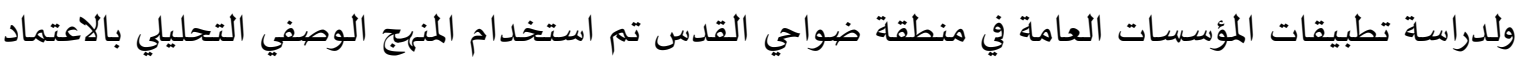

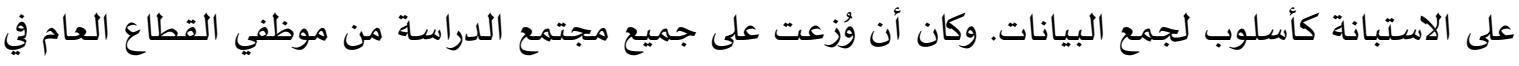

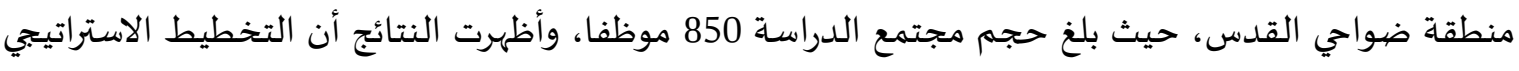

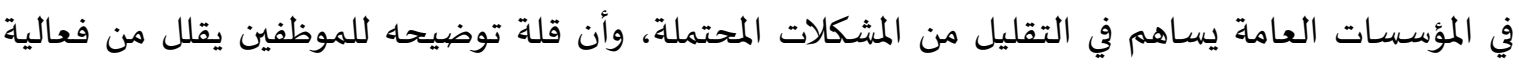

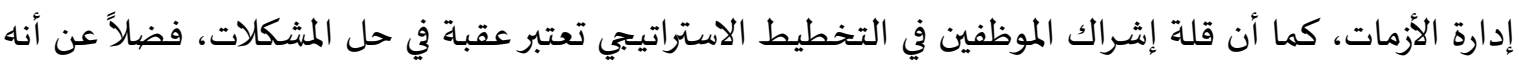
يكشف نقاط القوة والضعف في المؤسسة، وأن التخطيط الاستراتيجي يوفر معلومات تفيد اتخاذ القرارات وحل

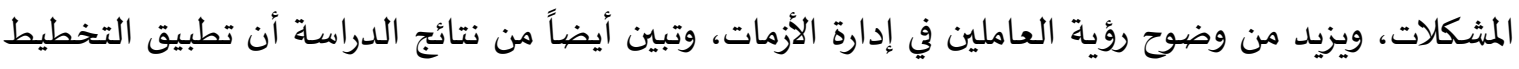

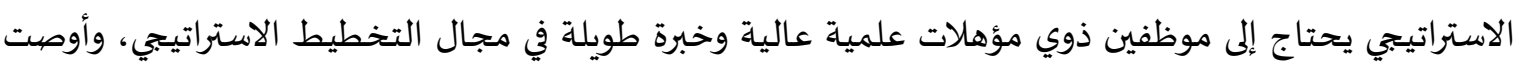

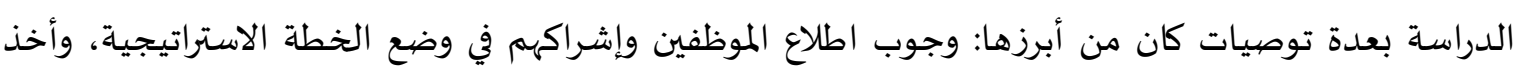

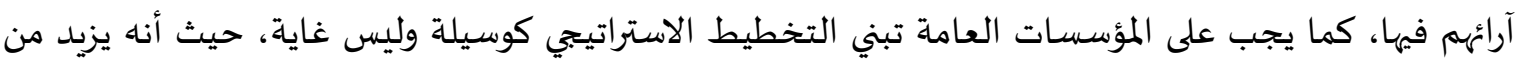

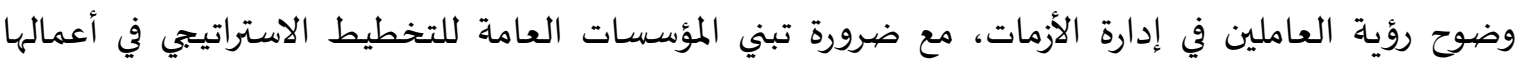

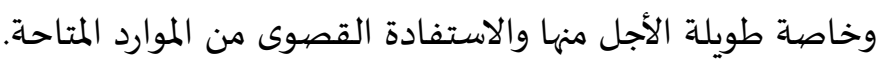
دراسة إيمان عبدالرحمن، 2019؛ هدفت الدراسة معرفة واقع إدارة الأزمات في مؤسسات التعليم العالي، الماتهات

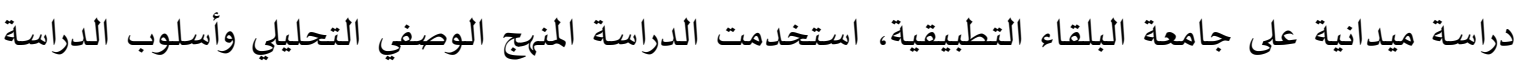

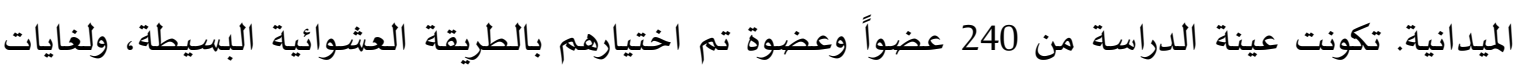

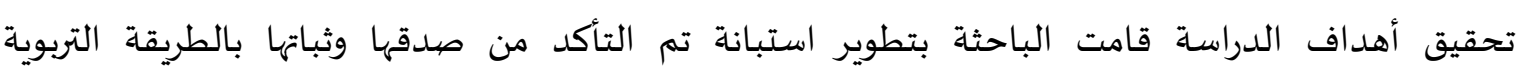
والاحصائية المناسبة، ثم تحليل البيانات من خلال برنامج الرزم الاحصائية للعلوم الاجتماعية (spss). وأظهرت

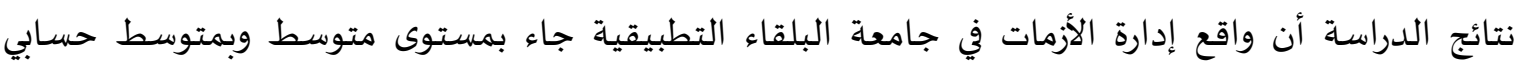

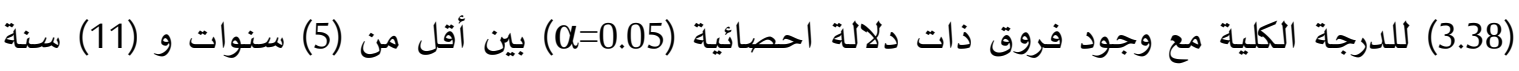

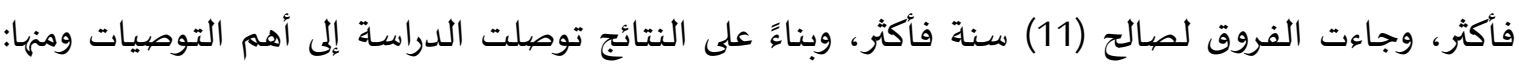

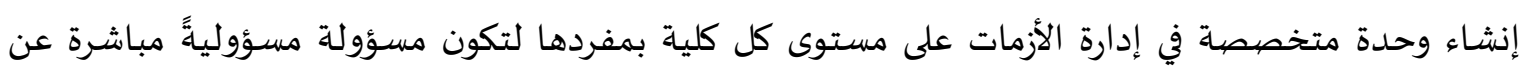

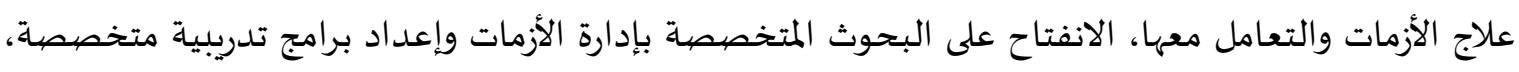

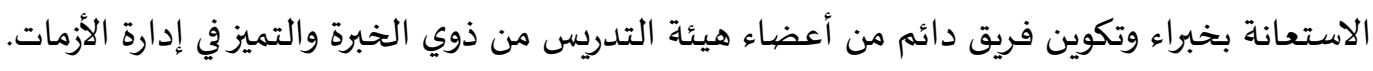

التعليق على الدراسـات السابقة: - الس

من خلال الاستعراض السابق للدراسات السابقة فقد تم التوصل إلى ما يلي:

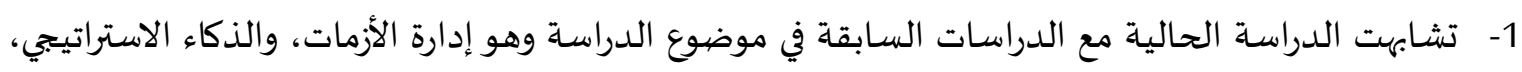
كما أنها اتفقت وتشابهت بأداة الدراسة ومنهج الدراسة الداسة.

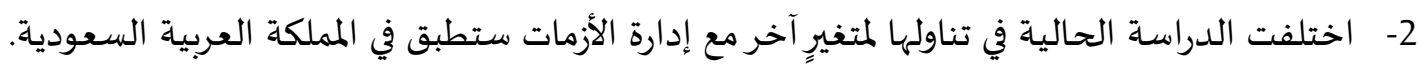

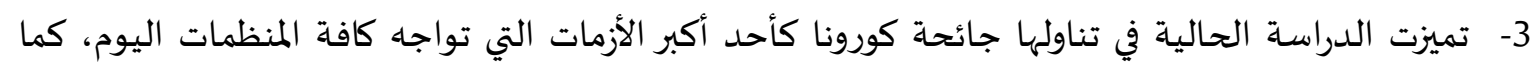

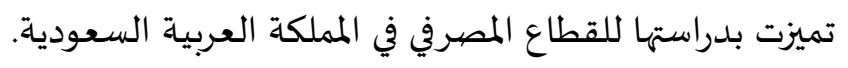




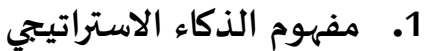

ينظر للذكاء بأنه القدرة التي وضعها الله في الإنسان حين ميزه عن سائر المخلوقات الأخرى بنعمة العقل

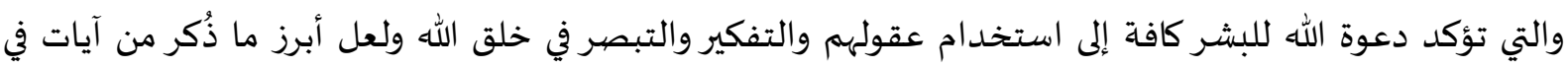

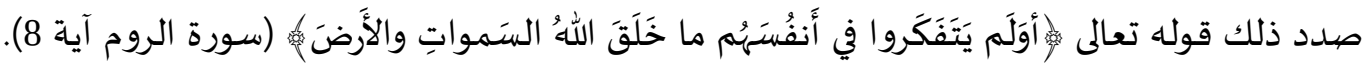

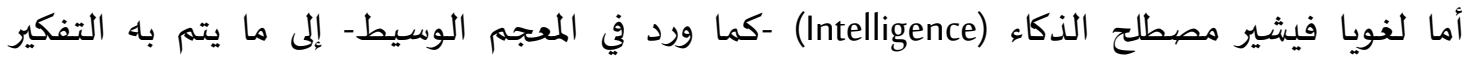

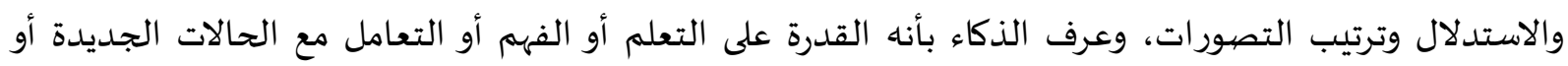

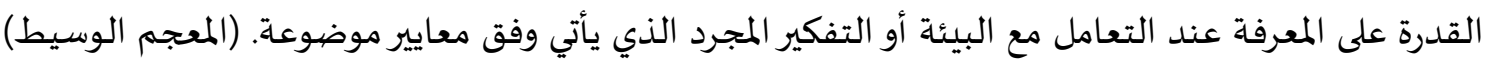

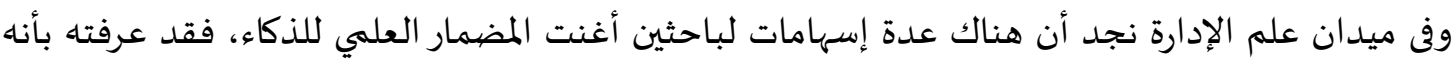

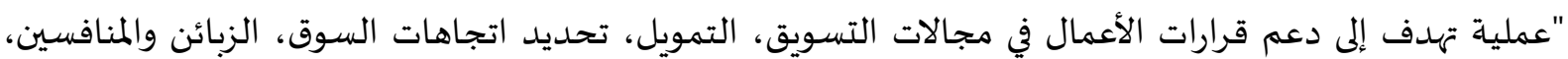

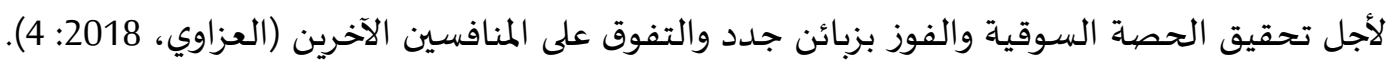

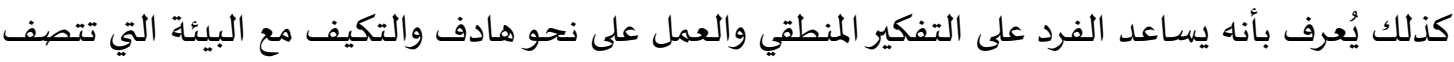

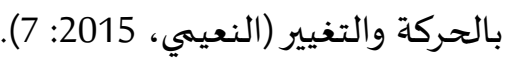

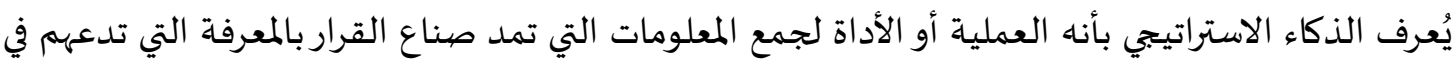

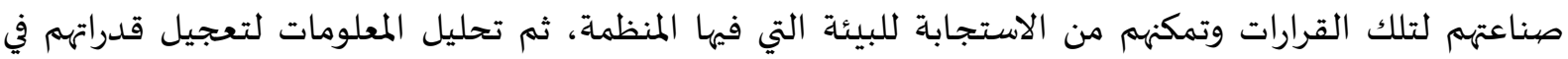

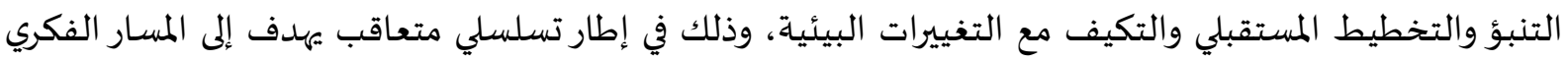

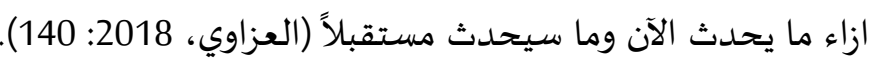
ويرى (14، 2017، et al،Kulhman بأنه ابتكار لخريطة طريق توجه صناع القاع القرار نحو صناعة قرارات أكثر

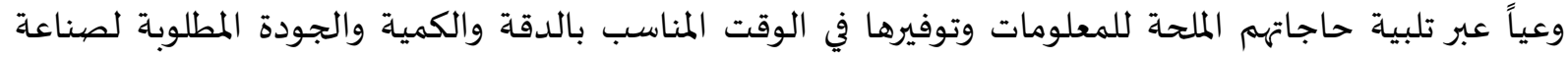
قراراتهم بعقلانية. بينما عرفه (عبد اللطيف، 2016: 32-33) بأنه الوظيفة التي تتعامل مع بيئة السوق والطلب وهوية الشركة والحصول على المصادر، والتغيرات البيئية والتنبؤ التكنولوجي والاجتماعي بغية تحقيق الانتشار والفاعلية البعيدة واكتساب الخبرة والحكمة العقلية.

استنادا إلى ما تقدم فإن الباحث يرى أن هناك تباين في اتجاهات التعريفات لا تنفي حقيقة الدور الجوهري للمعلومات في تشكيل مفهوم الذكاء الاستراتيجي، ودعم عمليات صناعة القرارات وصياغة السياسات والخطط والتنبؤ بتغيرات البيئة وبحركة المنافسين والتكيف معها، وكيف أن هذه المعلومات توفيل ودفر دعماً للقائد الذي يوسئ

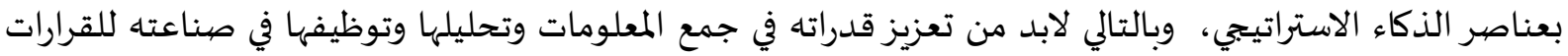
ورسمه للسياسات والخطط وهذا يتيح للباحث وضع مفهوم لهذا النمط من الذكاء الاستراتيجي بمستوى البحث لنش

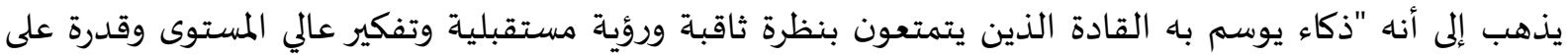
رفع الابداع من التركيز على نظام معلوماتي يتيح لهم استقصاء المعلومات ومعالجتها وتحليلها ليتسنى لهم توظيف أفكارهم في صناعة القرارات وصياغة الاستراتيجيات بمستوى عالي من الذكاء والقدرة على العمل". 
2. - 2 أهمية الذكاء الاستراتيجي

يمكن تشخيص جوانب الأهمية الخاصة بالذكاء الاستراتيجي من التعرف إلى الأدوار التي ينهض بها هذا

النمط من الذكاء، ومن هذه الأدوار ما يلي: (صالح وآخرون، 2017: 148-164)

$$
\text { دور دور الذكاء في ترسيخ السمات القيادية. }
$$

3. أهداف الذكاء الاستراتيجي:

إن للذكاء الاستراتيجي أهدافا حُددت بما يلي: (صالح وآخرون، 2017: 148-164)

أ- توفير تنبؤات وتحذيرات مبكرة بالهديدات المحيطة بالمنظمات واتخاذ الإجراءات الوقائية المائية بأجزائها.

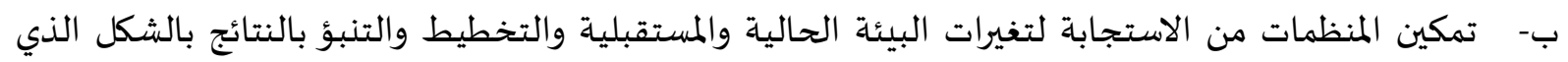
ينعكس إيجاباً على سمعتها وموقعها. ج- تشكيل القناعات لدى صناع القرارات وصياغة السياسات بوجوب الوصول إلى قرارات وسياسات إبداعية مُثلى.

د- النهوض بجمع المعلومات وتحليلها عن البيئة الخارجية وجعل المنظمات تتحالف في مجال البحث والتطوير.

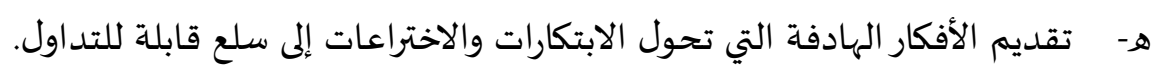

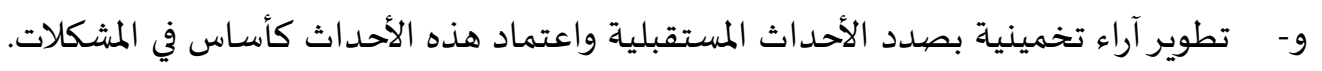
ز- توفير معلومات استراتيجية تمكن المنظمات من فهم التهديدات التي تحيط بها حالياً ومستقبليا.

4. خصائص الذكاء الاستراتيجي:

يتسم الذكاء الاستراتيجي كغيره من أنماط الذكاء بجملة من الخصائرائص الذه والسمات والموضحة بالشكل (2)

(2016: 3،Tham \& Kim)

أ- مرحلة الاستشعار (Sensing) بمؤثرات التغيرات الداخلية والخارجية وتشخيصها على مستوى المنظمة. ب- الجمع (Collecting) للبيانات ذات المغزى. ج- التنظيم (Organizing) للبيانات وهيكلتها في شكل مصيادر للمعلومات. د- المعالجة (Processing) للبيانات وتحويلها إلى معلومات

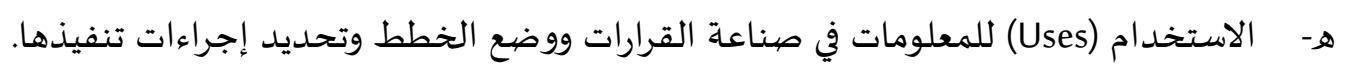

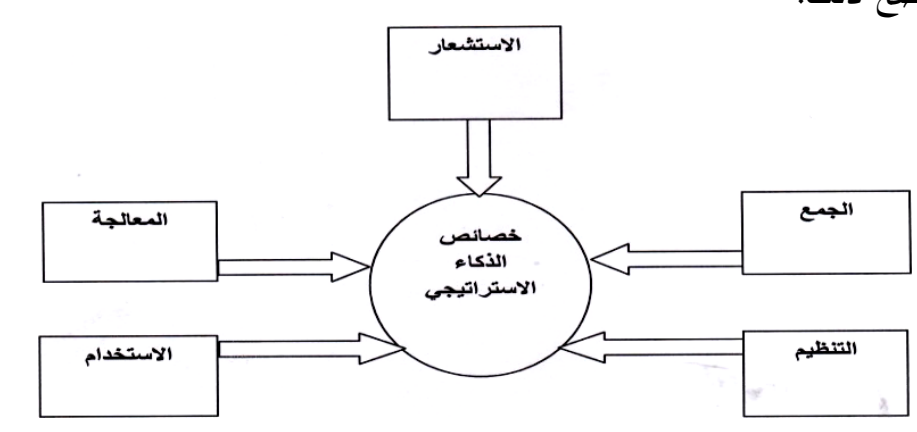




\section{شكل (2) خصيائص الذكاء الاستراتيجي}

Source: Tham، K. \& Kim، M. "Towards Strategic Intelligence with Anthology Based Enterprise modeling \& ABS"، Proceeding of the international business \& economic research،2016:3.

5. أبعاد الذكاء الاستراتيجي:

حدد الباحثون مجموعة أبعاد للذكاء الاستراتيجي والتي ستكون محور تركيز الدراسة الحالية والموضحة بالشكل (3) وهي كما يلي: (العزاوي، 2018: 152)، (الخفاجي، والبغدادي، 2015: 152)، (صالح وآخرون، 2017:

$$
\text { 1- الاستشراف (البصيرة): }
$$

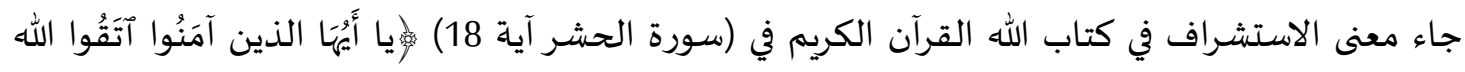

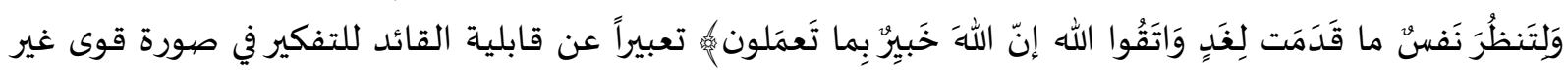

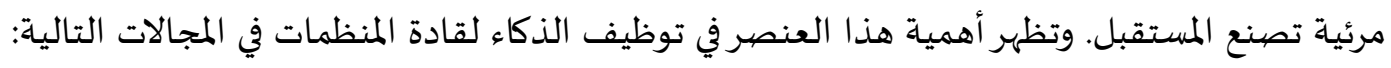

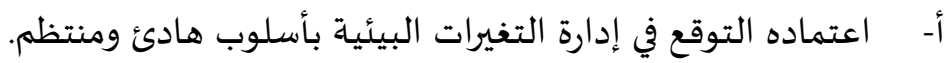

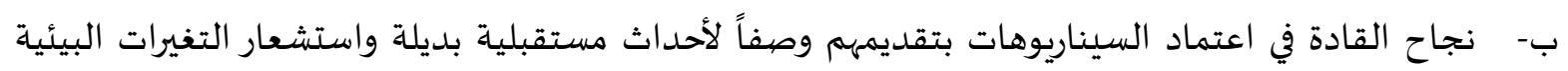

$$
\text { في صورة قوية غير مرئية. }
$$

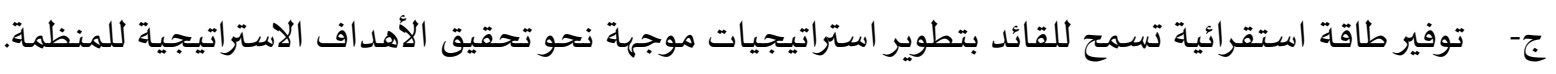

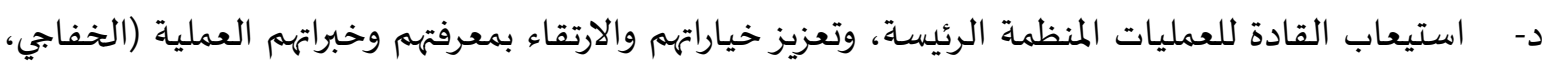

$$
\text { 2- التفكير المنظم: البغدادي، 2015: 152). }
$$

يعبر عن القدرة على توليف دمج العناصر أكثر من فصلها إلى أجزاء، ثم تحليلها مع بعضها، ثم تقييمها من حيث علاقتها بالكل، والتركيز على أسلوب تفاعلها مع بعضها من حيث نجاحها في خدمة أهداف النظام (النعيمي،

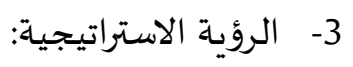

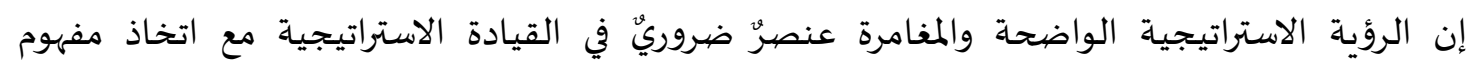

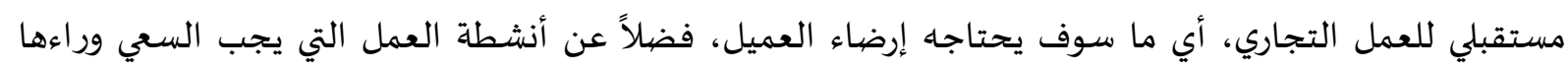
وأنواع حالات السوق طويلة الأجل التي يجب بناؤي لمأها مقارنة بالمنافسين، ونوعية الشراكة التي تسعى الشركة لإنشائها وتطويرها وتحديد تخطيط مسار الشركة باطلاع الإدارة العليا على الطريق والتوجاه، مع الإجابة على الأسئلة الآتية:

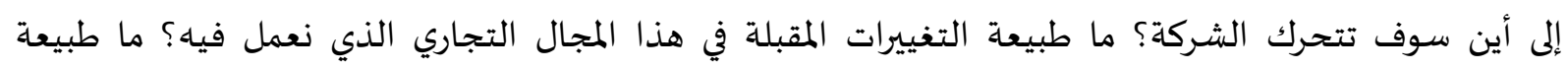

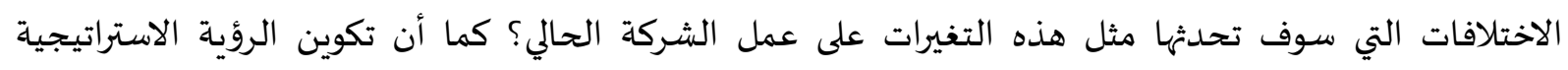

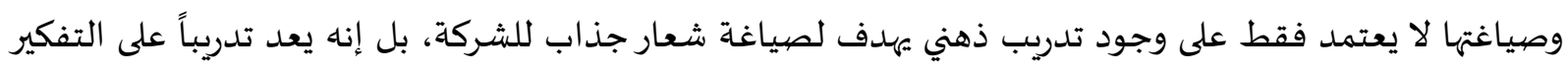

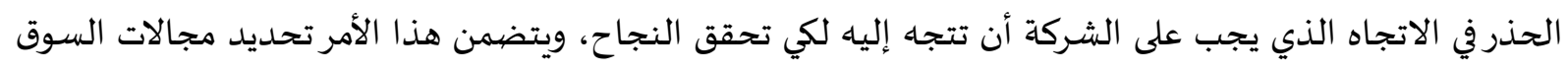

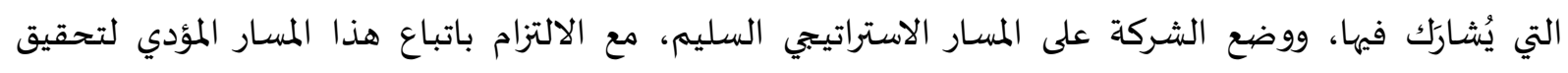

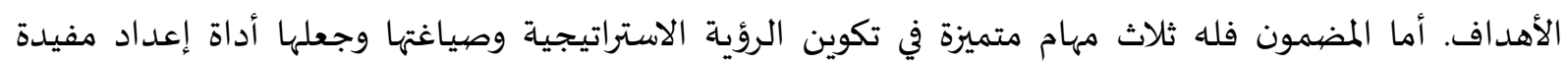

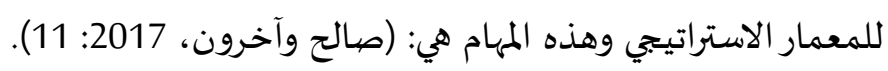


أ- ـ التوصل إلى مضمون رسالة مستهدفة توضح الأعمال التجارية التي تقوم بها الشركة حاليا وتوضح كيان

$$
\text { الشركة ومكانتها أو وضعها في الوقت الحالي. }
$$

ب- استخدام مضمون الرسالة المستهدفة كأساس لتحديد مسار طويل المدى، واختيار ما يجب الاتجاه إليه وتخطيط المسار الاستراتيجي الذي يجب على الشركة المرسيه أن تتبعه.

ج- التعبير عن الرؤية الاستراتيجية بألفاظ بسيطة ومثيرة، تزيد من مدى المارئ الالتزام على مستوى الشركة بأكملها.

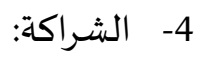

تعكس الشراكة قدرة القائد الذكي استراتيجيا على إجادته في إقامة تحالفات استراتيجية، أي رؤية شاملة للشراكة بإبرامه اتفاقيات تعاونية وتحالفات أو اندماجيات مع شركات أخرى في صهورة شبكات استراتيجية، إندادئ وهنا يتحدد دور الشراكات في الارتقاء بقدرات قادة المنظمات وذلك كونها: أ- أحد اتجاهات التنظيم المعاصرة التي تمهد السبيل إلى تحسين كفاءة الشركاء واشتراكهم في أداء المهمات وتقليل التكاليف وتحويل تنافسهم إلى تعاون. ب- أحد آليات التأقلم مع تحديات البيئة المضطربة، واقتناص الفرص الناتجة عن التطورات التهات التكنولوجية، وضمان انسيابية الخبرات والأفكار بين الشركاء. ج- إطار عمل تعاوني للتشارك في الموارد النادرة وفي تهديدات الدخول إلى الأسواق الجديدة، وكذلك التكيف مع البينة المتغيرة. د- - تُشبع حاجات المستفيدين وتوسيع نطاق خدمتهم، مع (الإبداع في حل المشكلات، والتفوق في الأداء، ودعم الاستثمار الطويل الأمد) ثم تحقيق قيمة أكبر لأطراف الشراكة. هـ- تتخلص من الجمود المنظمي وتقليل المخاطرة الناتجة عن تصنيع المنتجات الجديدة وتسويقها. (العزاوي، (152: 2018 5تعبر عن الفعل الذي يدفع الفرد إلى تبني وجهه نظر ملائمة لإنجاز العمل المكلف باه بشكل مرض، كذلك

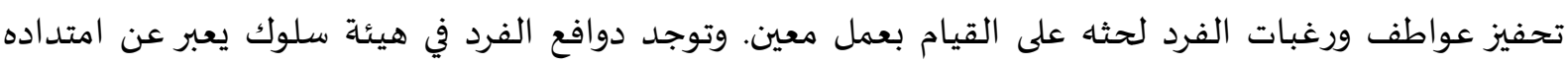

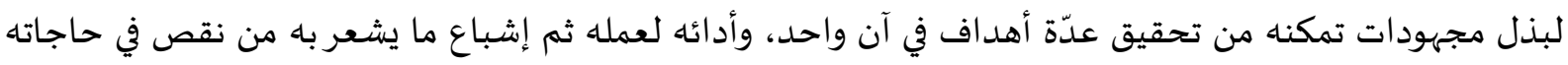

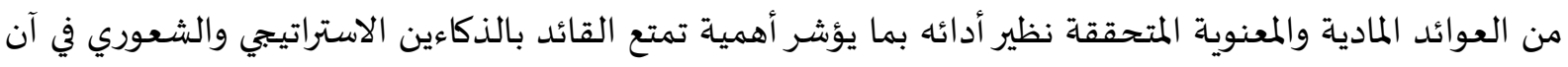

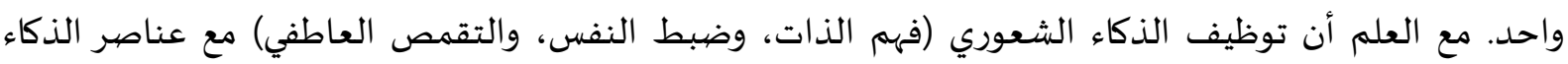

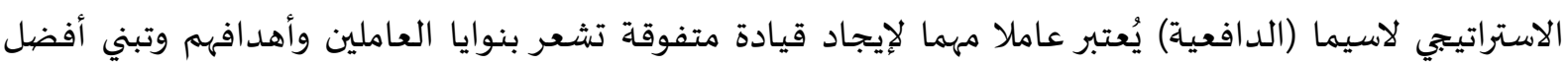

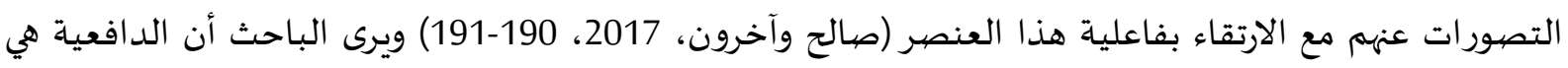

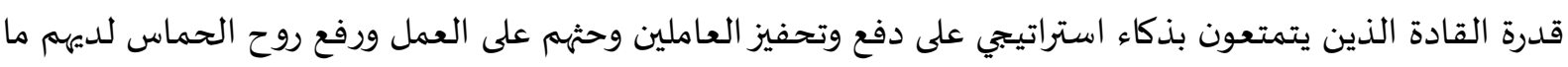
يجعل المنظمة تحقق ميزة تنافسية.

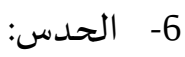

يصفه (خير الله) بأنه (الصوت الداخلي الذي يولّّد لدينا مشاعر ضيد قراراتنا أو معها بشكل عام لا سيّما إذا

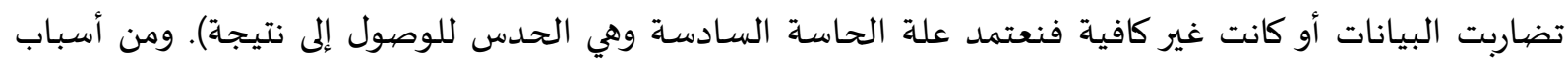
زيادة الحدس: (خير الله، 2018: 15) أ- التدريب على التنبؤ بالمستقبل.

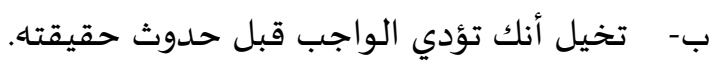




$$
\begin{array}{r}
\text { و- } \\
\text { و- }
\end{array}
$$

واستناداً إلى ما تقدم يمكن توضيح أبعاد الذكاء الاستراتيجي بالشكل (3)

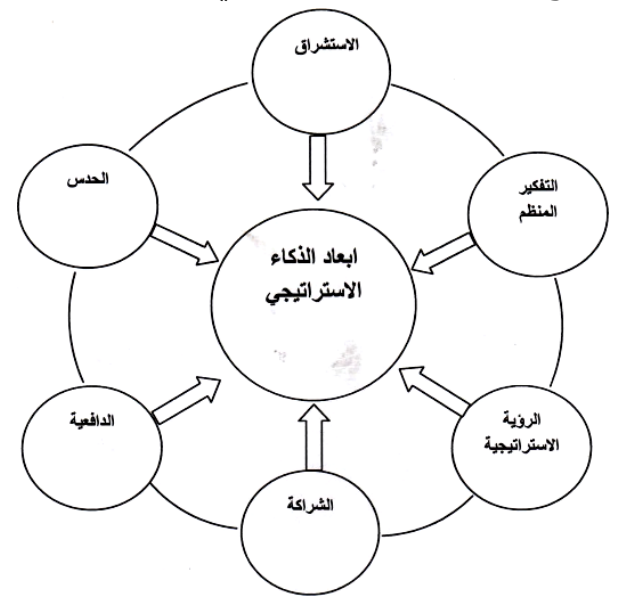

شكل (3) أبعاد الذكاء الاستراتيجي

"عمران، نضال عبدالهادي، أثر الذكاء الاستراتيجي على الإبداع التنظيمي" التهاد التئي

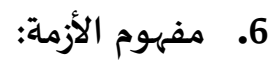

تشير الأدبيات في مجال الأزمات إلى أن مفهوم الأزمة نشأ في نطاق العلوم الطبية، ليشير إلى اللحظة المرضية

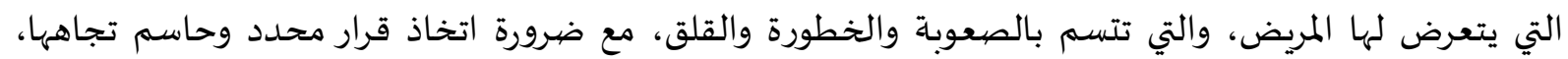

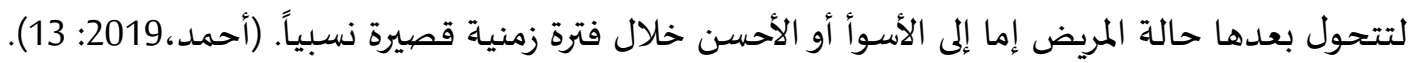

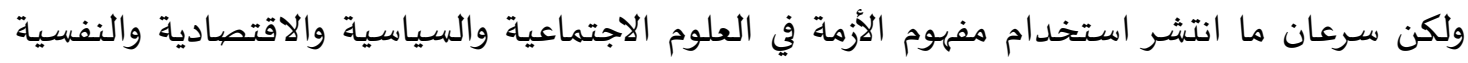

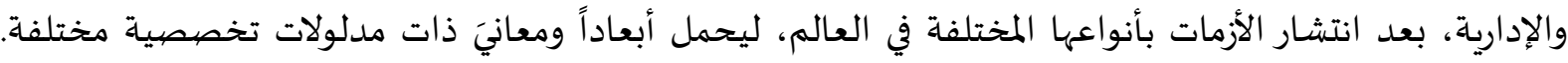

(إسليم، 2017: 12).

لقد حظيت الأزمات باهتمام الباحثين في مجال العلوم الإدارية، فمنهم من تناول الأزمة وأبعادها وخصائصها

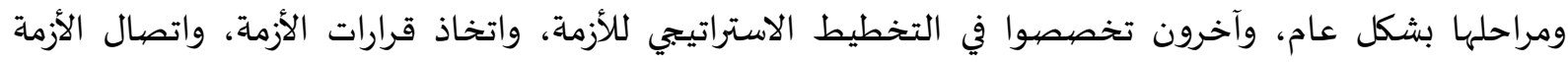

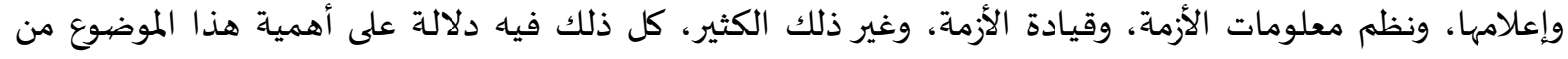

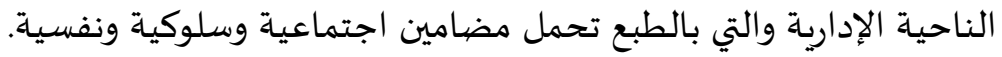
يشير مفهوم الأزمة إدارياً إلى نقطة تحول في الكيان الإداري نحو الأسوأ أو الأفضل فتثير والئ حالة من الاستقرار

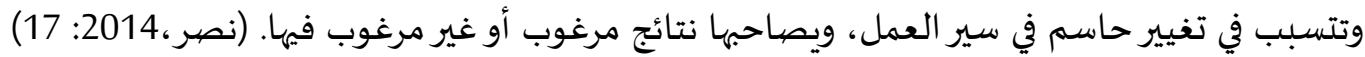

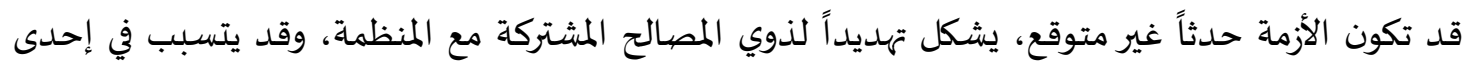
تأثيرات سلبية على أدائها. (2015: 22،Parnell) كما أن الأزمة حالة غير عادية تخرج عن نطاق التحكم والسيطرة، وتؤدي إلى توقف حركة العمل أو هبوطها

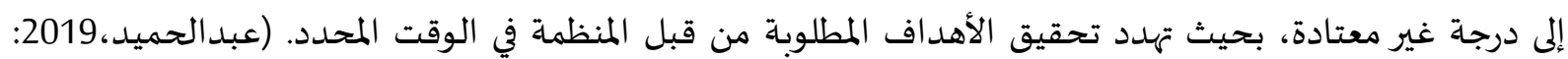


يشير البعض أن الأزمة قد تدل على مشكلة ظهرت في الأفق وتم التغاضي عنها حتى استفحلت فصارت أزمة

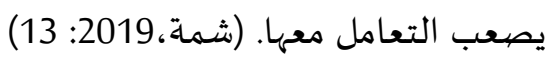

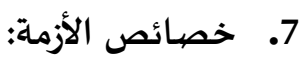

يتفق الباحثون في تعريفاتهم على ضرورة توفر مجموعة من السمات في موقف معين أو حالة معينة حتى

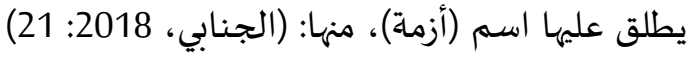

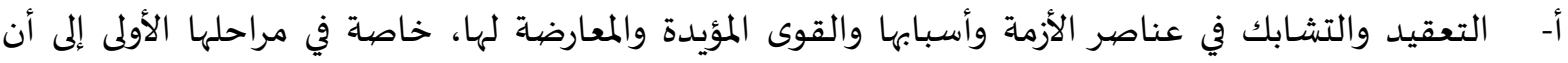
تتجلى مع مرور الوقت.

ب- نقص المعلومات وقلة البيانات: حيث يشهد الموقف الأزموي نقصاً للمعلومات التي تساعد على صنع القرار،

وهذا النقص قد يكون متعمداً أو غير متعمدٍ.

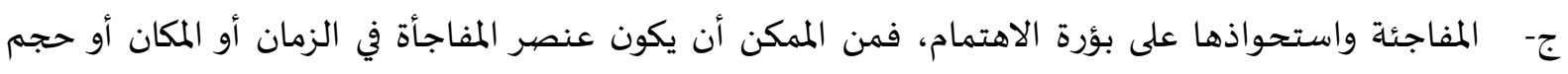

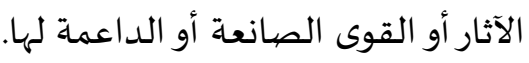

د- تزايد الضغوط الداخلية والخارجية على الكيان الإداري، سواء أكانت في شكل ضغوط الفوان نفسية أو مادية مما

يُصعب من عملية اتخاذ القرارات من قبل الإداريين أو متخذي القرار.

هـ - الصدمة العنيفة والشلل الفكري الذي يحصل للموظفين لدى الإدارات المختلفة في الكيان الإداري لهول

الصدمة والمفاجأة التي لم يكن يتوقع حدوثها.

و- انتشار حالة من الخوف والهلع على المستقبل والأموال والممتلكات والأرواح.

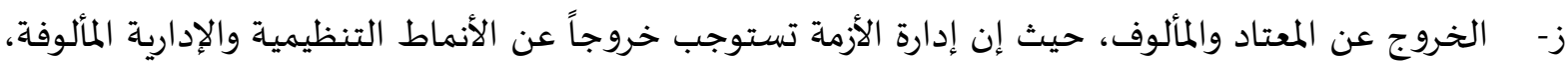
واستخدام وسائل غير عادية في بعض الحالات حيث إن وجود تهديد مباشر وصريح للكيان الإداري والعاملين

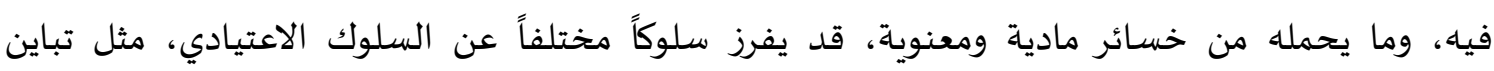

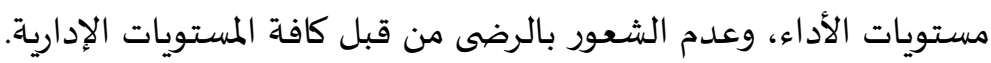

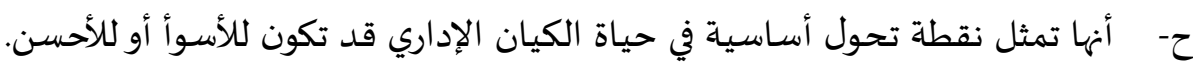

8. - مناهج تشخيص الأزمات:

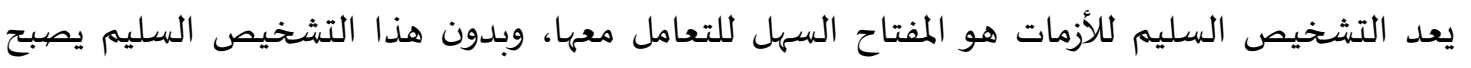

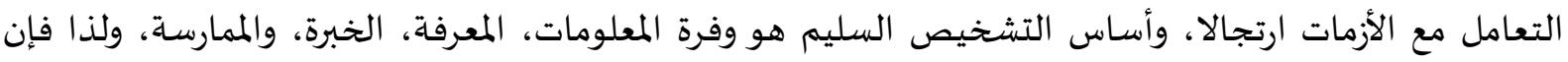

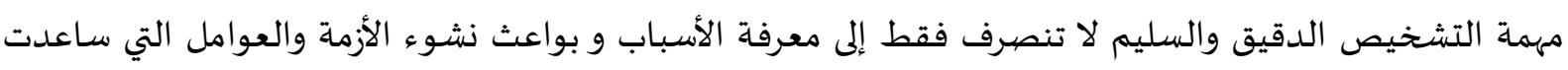

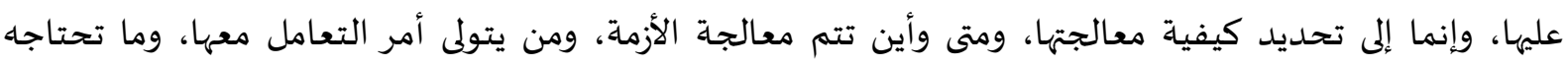

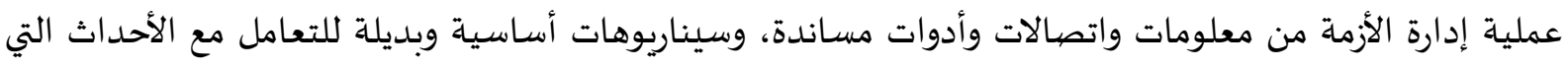

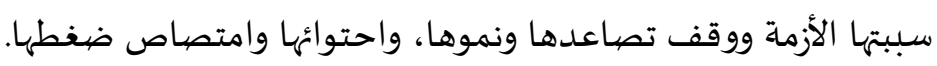
هناك عدة طرق ومناهج يمكن من خلالها تشخيص الأزمة، وبالتالي القدرة على التعامل معها، وفيما يأتي

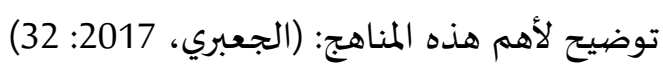

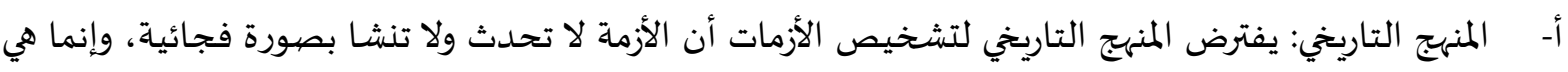

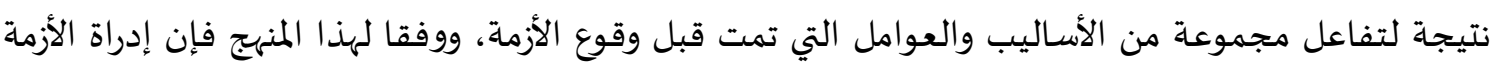
والتعامل معها يجب أن يكون في ضوء المعرفة الواضحة والكاملة والمتكاملة للماضي التاريخي فهو مفتاح التهاح النجاح في إدارتها وموضع جميع التصيورات لعلاجها. 
ب- المنهج النظمي: ينظر للأزمة في هذا المنهج على أنها نظام متكامل يتكون من مجموعة من العناصر هي: (جعفر،

1. مدخلات الأزمة: يبدأ تشخيص الأزمة وتوصيفها من خلال دراسة وتحليل مدخلات الأزمة، فالأزمة نظام، ولكل

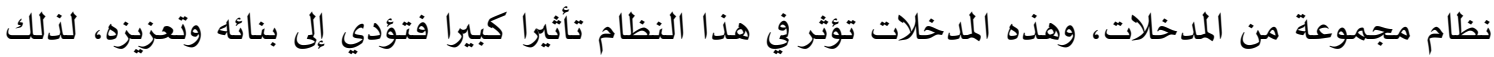
يجب تحديد جميع مدخلات النظام التي وقعت فيه الأزمة وهذا يساعدها في تحديد نقاط القوة ونقاط

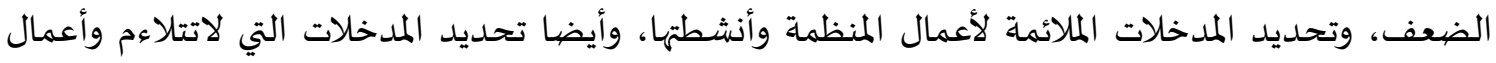
المنظمة وأنشطتها، فهذا يساعدها على إدارة الأزمة والتعامل معها بصورة كفؤة و فاعلة تقود إلى تعزيز النجاح المنظمي. 2. العمليات التشغيلية للأزمة: ويقصد بها مجموعة العمليات التشغيلية التي تُحدث تفاعلاٍٍ محددة بين مجموعة من المدخلات بصورة تؤدي إلى تعزيز الأزمة وزيادة قوتها وحدتها، وتؤدي إلى اخراج هذه الأزمة إلى بيئة المنظمة، وهنا لابد من التأكيد على الدور البارز الذي تلعبه هذه العمليات التشغيلية في إنجاح الأزمة، فتوافر

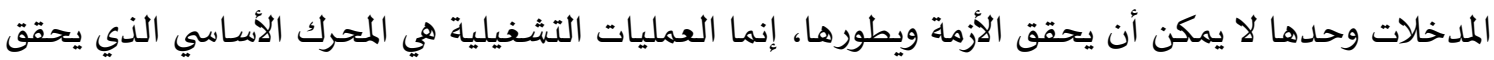

3. المخرجات الأزموية: تتجسد هذه المخرجات فيما نجم عن العمليات التشغيلية للأزمة التي جرت على المدخلات

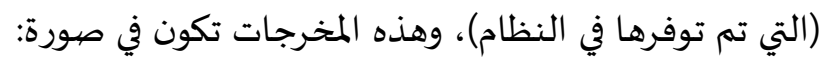

نتائج الأزماة وآثارها التي تكون ملموسة وواضحة لأفراد المنظمة والبيئة الخارجية للمنظمة. نتائج وآثار لا يلمسها الجميع، بل يدركها ويشعر بها أطراف محددة فقط (مثل الإدارة العليا للمنظمة على

4. التخذية العكسية: عند استخدام مدخل النظم في تشخيص الأزمة وتوصيفها، فإنه لابد من الاعتماد على

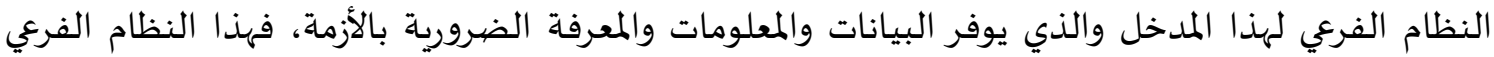

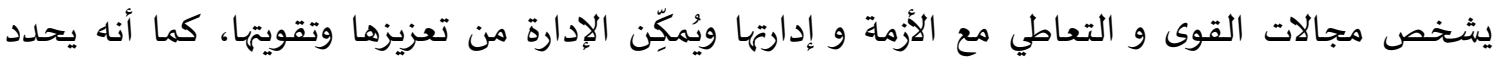

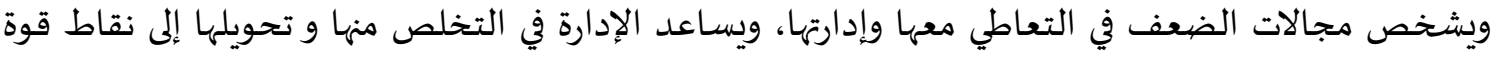
قدر المستطاع، من جانب آخر فإن هذا النظام الفرعي (التغذية العكسية) يساعد إدارة المنظمة في تحديد

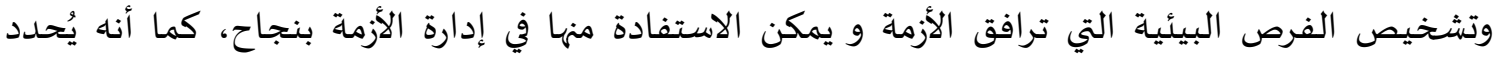

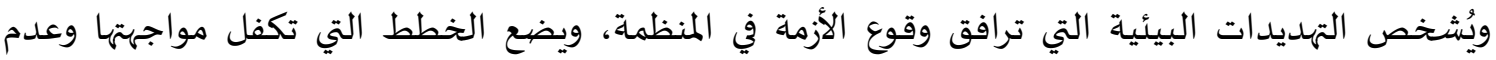
تفاقمها وعدم تعاظم تأثيراتها السلبية على أعمال المنظمة وأنشطتها.

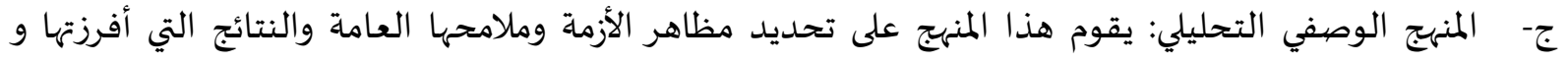
تأثيرها على الوضع العام في الدولة، وينتهي هذا المنهج بتوصيف الأزمة وعرض أبعادها و جوانها والمرحلة التي وصلت إليها والتداعيات التي قد تصل إليها. د- منهج دراسة الحالة: يعتمد هذا المنهج على دراسة كل أزمة على حدة لاكتساب الخبرة في التعامل معها، وذلك

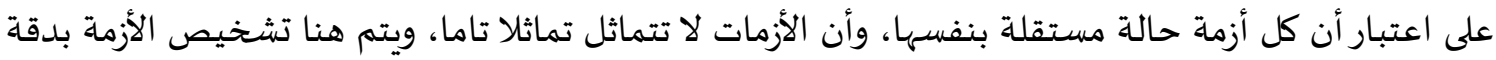

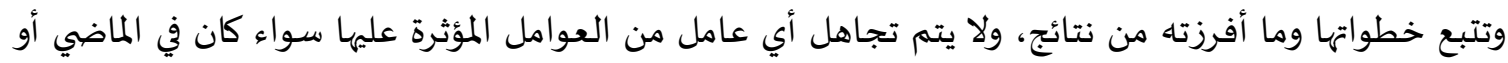
الحاضر. هـ المنهج البيئي: يفترض هذا المنهج أن أي أزمة هي وليدة بيئتها، وهناك عوامل خاصية وعوامل عامة توفر الظروف

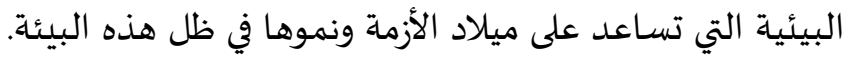


و- منهج الدراسات المقارنة: يقوم هذا المنهج على دراسة الأزمات التي تمت في الماضي ومقارنتها موضوعيا بالأزمات

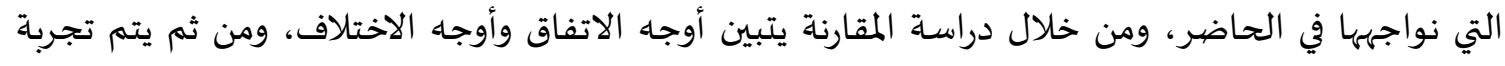

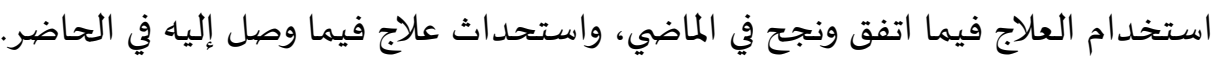

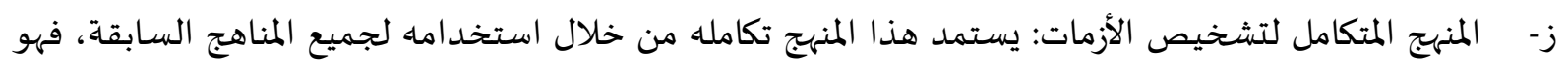

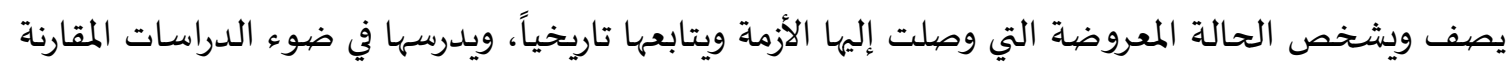
التي تمت في الماضي، بالإضافة إلى دراسة الأزمة كنظام.

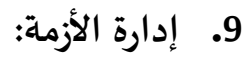

نشأ علم إدارة الأزمات في محاولة من المتخصصين لدعم متخذ القرار بنظم المعلومات والوسائل والإجراءات

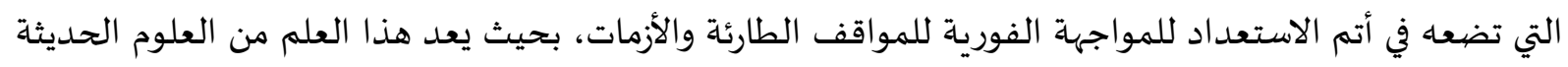

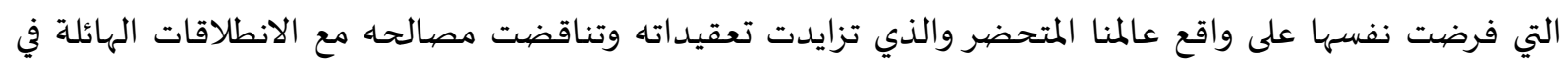

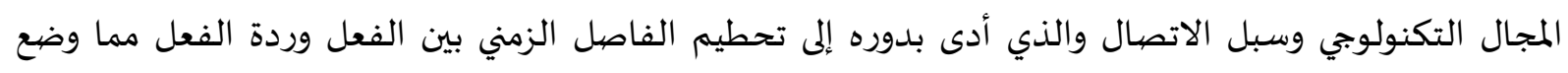

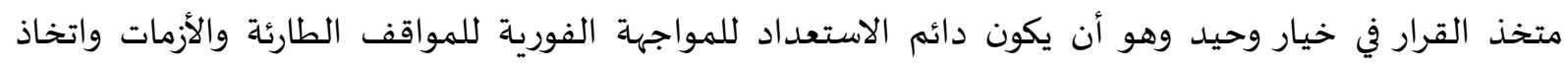

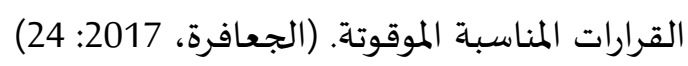

10. تعريف إدارة الأزمات:

تختص إدارة الأزمة بالتعامل مع الأزمات على ضوء الاستعدداد والمعرفة والوعي، والإمكانات المتوفرة والمهارات الإدات

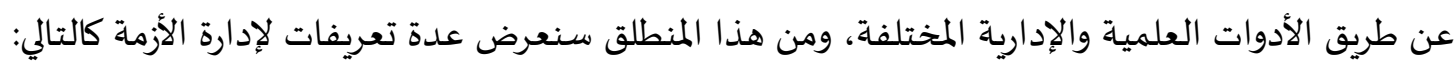

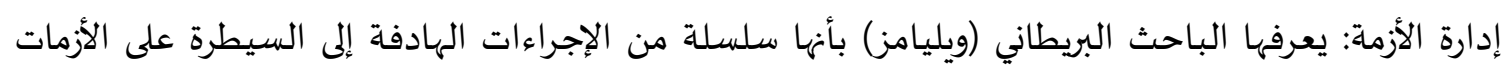

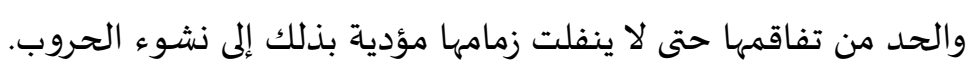

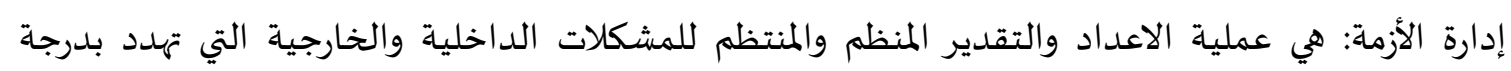
خطيرة سمعة المنظمة وربحيتها أو بقائها في السوق. إدارة الأزمة: هي نشاط هادف يقوم على البحث والحصول على المعلومات اللازمة التي تمكن الإدارة بالتنبؤ

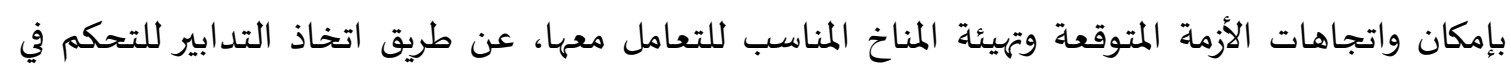

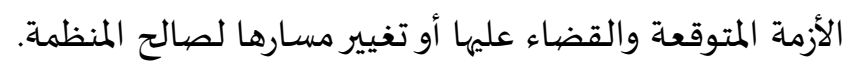
إدارة الأزمات إذن هي عملية رشيدة تُبنى على العلم والمعرفة وتعمل على وقاية المؤسسة والأرتقاء بأدائها،

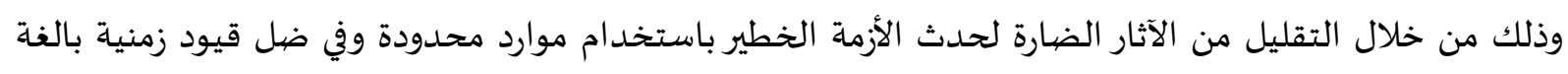

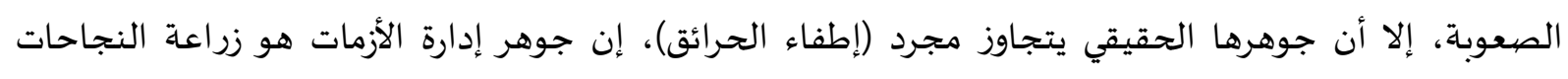

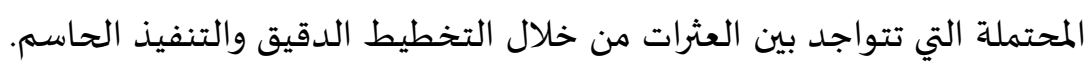

11. متطلبات إدارة الأزمات:

إن التعامل مع الأزمات يستدعي توفير مناخ ملائم يتيح مجالا واسعا للتحرك بدون التمات أي قيود أو معوقات، وفيما

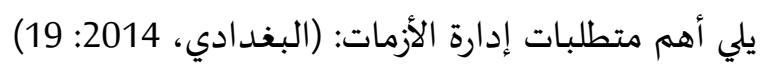

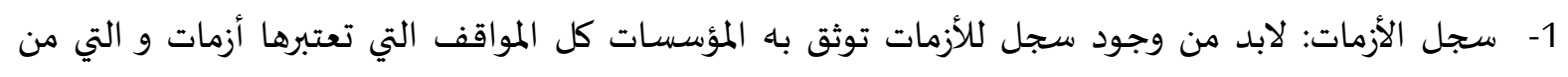

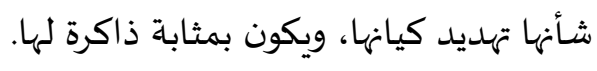


2- فريق إدارة الأزمات: هو مجموعة من الأفراد المنتقين بعناية - وفقا لخبرات سابقة - أو لدراسات متعمقة في

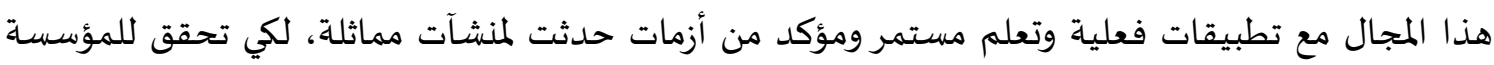

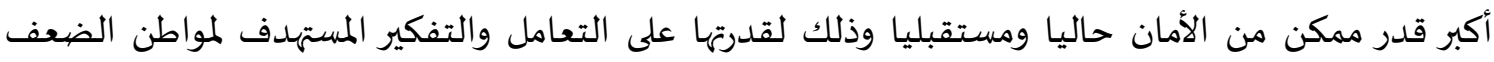
والخطر التي يمكن أن تتسبب في أزمات ووضع الخمان الخطط لتوقي حدوثها والتعامل معها فور استشعارها.

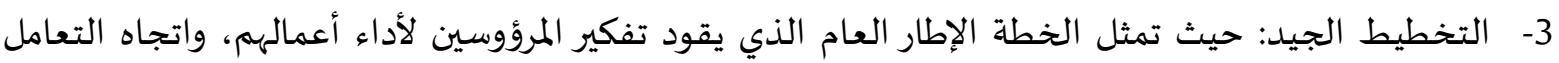

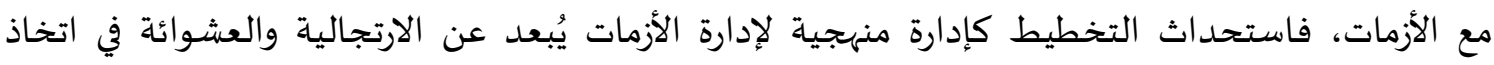
القرارات. 4- التواجد المستمر: من الصعب معالجة الأزمات الكبيرة إلا من خلال تواجد أعضاء الفريق بشكل مستمر في

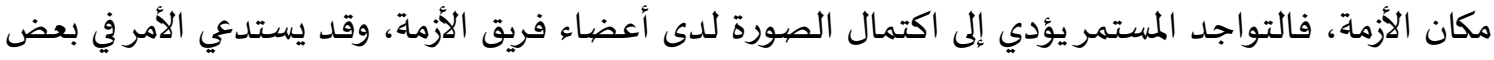
الأحيان إلى تدخلهم الفوري والمباشر.

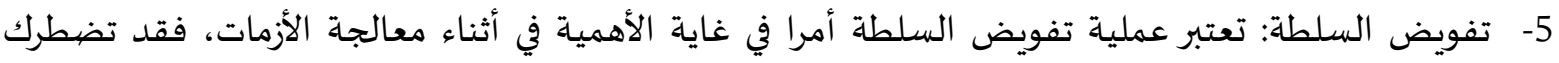

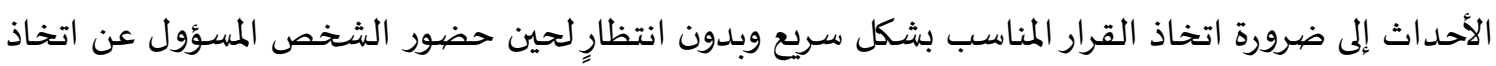

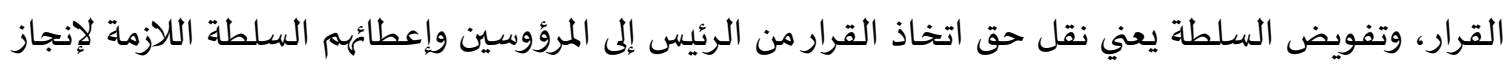

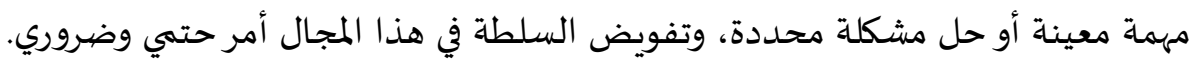

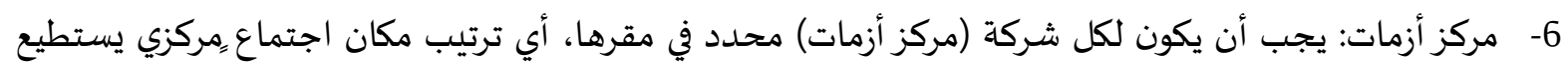

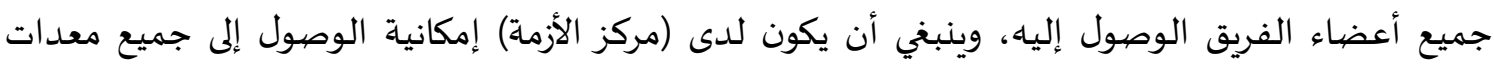

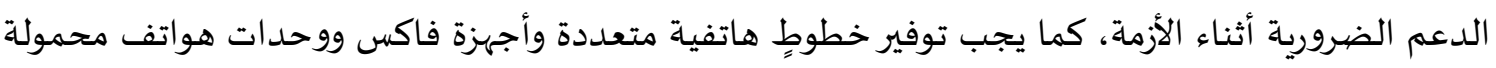

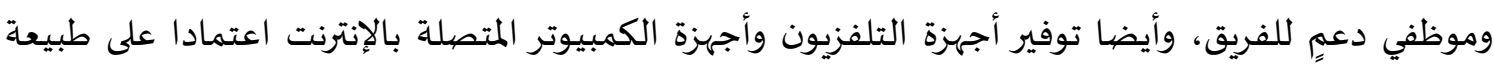

تتميز إدارة الأزمة بعدة أبعاد حسب طبيعة موضوع الأزمة: (جعفر، 2017: 302)

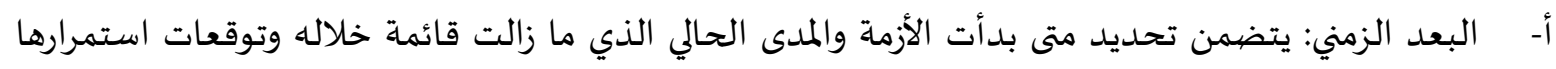

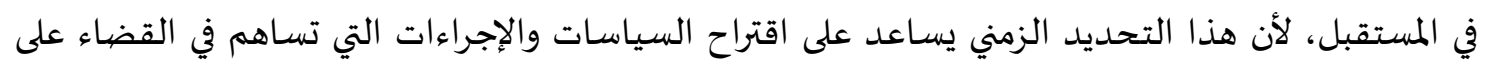

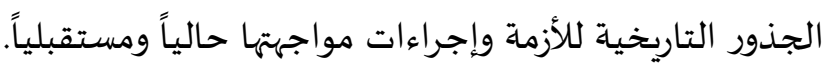

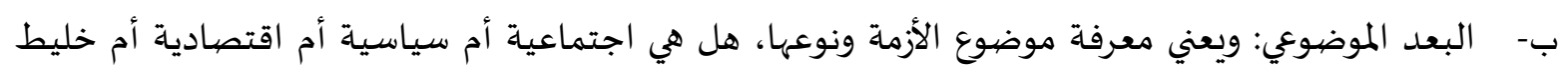
من نوع أو أكثر من تلك الأنواع.

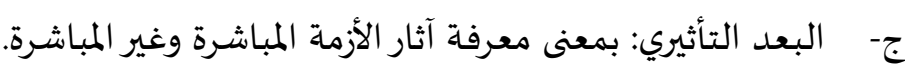

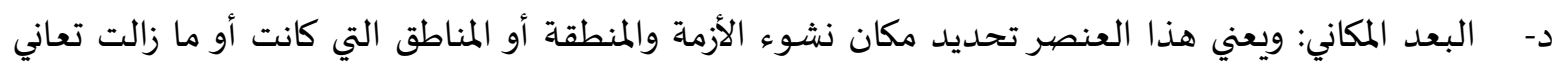

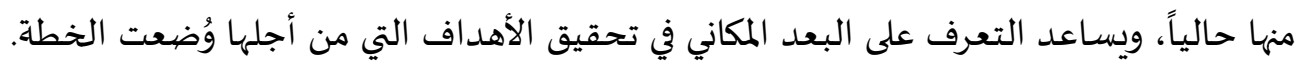
هـ- البعد البشري: يتضمن هذا العنصر تحديد الأفراد الذين تشملهم الأزمة ونوعياتهم.

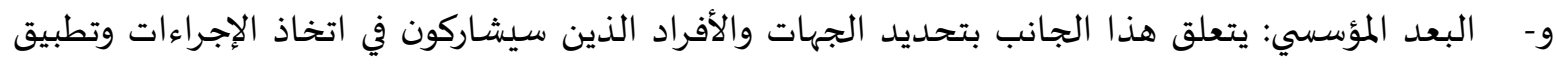
السياسات الإدارية والتنظيمية اللازمة.

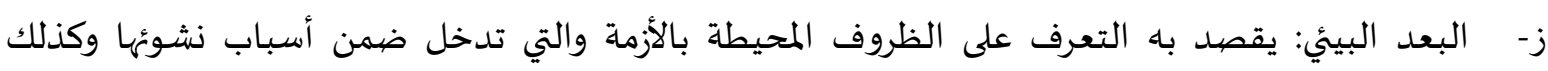
التعرف على المتغيرات المختلفة التي تسبب في نشوئها واستمرارها حالياً ومستقبلياً. 
4- - منهجية الدراسـة وإجراءاتها.

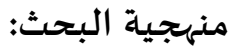

تم استخدام المنهج الوصفي الارتباطي كونه الأفضل لمثل هذه الدراسات واستخدمت الاستبانة كأداة لجمع

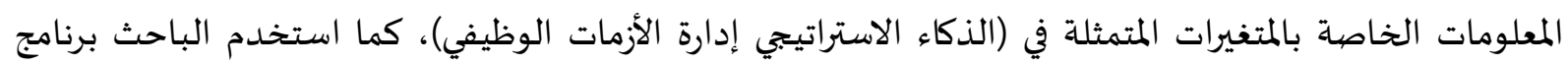
الحزم الإحصائية (SPSS) لتفسير تلك البيانات والخروج منها بنتائج وتوصيات

مجتمع الدراسة:

يتكون مجتمع الدراسة من جميع العاملين في المصارف بمدينتي خميس مشيط وأبها والبالغ عددهم (2000)

موظفاً.

عينة الدراسـة:

عينة عشوائية بسيطة من مجتمع الدراسـة بلغت (154) موظفاً من موظفي المصارف في مدينتي خميس

مشيط وأبها.

أ- خصائص عينة الدراسة:

تقوم هذه الدراسة على عدد من المتغيرات المستقلة المتعلقة بالخصائص الوظيفية والشخصية لأفراد

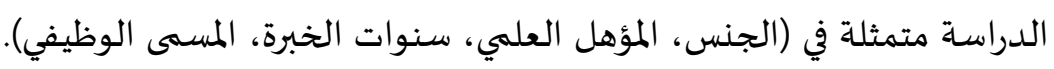

وكانت مواصفات العينة على النحو التالي:

جدول (1) توزيع عينة الدراسة بناءً على متغير الجنس النس

\begin{tabular}{|c|c|c|}
\hline النسبة المئوية\%\% & التكرار & \\
\hline 97.4 & 150 & ذكر \\
\hline 2.6 & 4 & أنثى \\
\hline 100.0 & 154 & Total \\
\hline
\end{tabular}

تبين من خلال نتائج الجدول (1) أن ما نسبته 97.4 من أفراد العينة كانوا ذكورا، والباقي كُن إناثا بنسبة قليلة جداً بلغت 2.6\%.

جدول (2) توزيع عينة الدراسة بناءً على متغير المؤهل العلمي

\begin{tabular}{|c|c|c|}
\hline النسبة المئوية\%\% & التكرار & \\
\hline 32.5 & 50 & دبلوم \\
\hline 53.2 & 82 & بكالوريوس \\
\hline 13.0 & 20 & ماجستير \\
\hline 1.3 & 2 & دكتوراه \\
\hline 100.0 & 154 & Total \\
\hline
\end{tabular}

تبين من خلال نتائج الجدول (2) أن ما نسبته 32.5\% من أفراد العينة مؤهلهم دبلوم، وأن ما نسبته

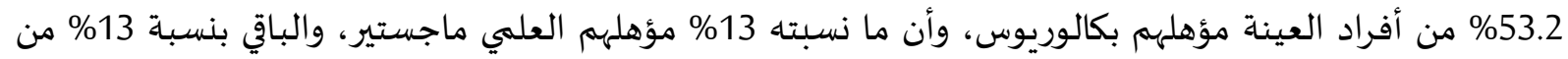
أفراد العينة من حملة شهادة الدكتوراه. 


\section{جدول (3) توزيع عينة الدراسة بناءً على متفير سنوات الخدمة}

\begin{tabular}{|c|c|c|}
\hline النسبة المئوية\%\% & التكرار & \\
\hline 3.9 & 6 & أقل من سنة \\
\hline 22.7 & 35 & من 1 - أقل من 5 سنوات \\
\hline 37.0 & 57 & من 5 - أقل من 10 سنوات \\
\hline 36.4 & 56 & من 10 سنوات فأكثر \\
\hline 100.0 & 154 & Total \\
\hline
\end{tabular}

تبين من خلال نتائج الجدول (3) أن ما نسبته 3.9\% سنوات الخبرة لديهم أقل من سنة، وأن ما نسبته

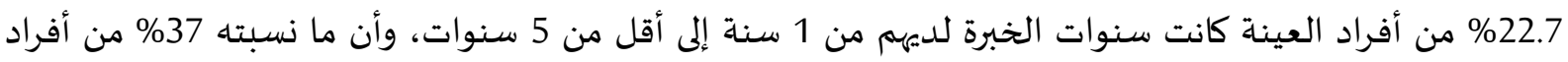

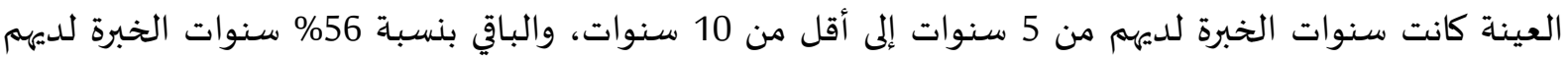
أكبر من 10 سنوات.

جدول (4) توزيع عينة الدراسـة بناءً على متغير المسمى الوظيفي

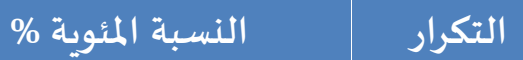

\begin{tabular}{|c|c|c|}
\hline 67.5 & 104 & موظف \\
\hline 7.8 & 12 & رئيس قسىم \\
\hline 10.4 & 16 & مدير \\
\hline 14.3 & 22 & Total \\
\hline 100.0 & 154 & أخرى \\
\hline
\end{tabular}

تبين من خلال نتائج الجدول (4) أن ما نسبته 67.5\% من أفراد العينة مسماهم الوظيفي موظفون، وأن ما

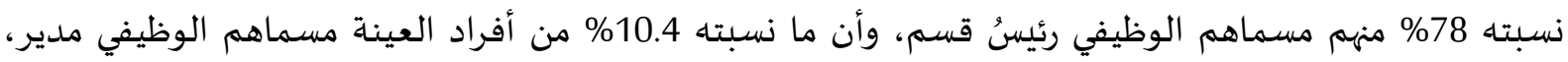

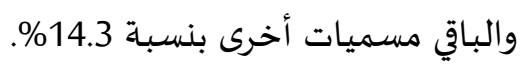

$$
\text { أسلوب جمع البيانات: }
$$

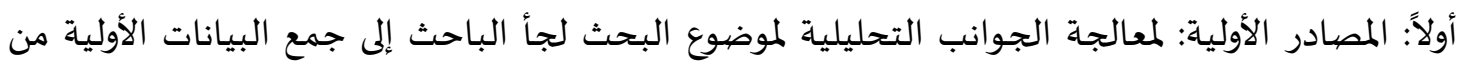

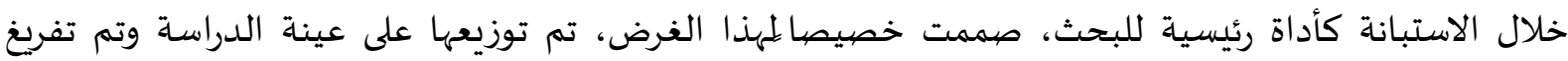
البيانات وتحليلها باستخدام البرنامج الإحصائي SPSS "، Statistical Package for the Social Sciences ، الإصيدار (24).

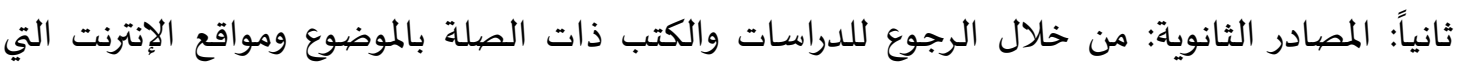
تناولت إطار الدراسة ومتغيراتها مثل المجلات والدوريات العلمية ومواقع المكتبات الإلكترونية مثل المنهل.

$$
\text { أداة وطريقة جمع البيانات: }
$$

$$
\text { تكونت أداة الدراسة من ثلاث أقيانات: }
$$

القسم الأول: ويشتمل على البيانات الشخصية: (النوع، العمر، المؤهل العلمي، عدد سنوات الخدات الخبرة، المسمى

القسم الثاني: الذكاء الاستراتيجي، وتكون من (25) عبارة وتتكون من الأبعاد التالية: 


$$
\begin{aligned}
& \text { البعد الخامس: الشراكة، ويتكون من (5) عبارات. } \\
& \text { البعد الرابع: التحفيز، ويتكون من (5) عبارات. } \\
& \text { البعد الثالث: التفكير، ويتكون من (5) عبارات. } \\
& \text { البعد الثاني: الرؤية، ويتكون من (5) عبارات. } \\
& \text { البعد الأول: الاستشراف، ويتكون من (5) عبارات. } \\
& \text { القسم الثالث: إدارة الأزمات، وتكون من (10) عبارات. }
\end{aligned}
$$

أسلوب تحليل البيانات:

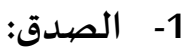

أ- الصدق الظاهري: وذلك من خلال عرض أداة الدراسة على عدد من المحكمين المتخصصين، وذلك بعرض

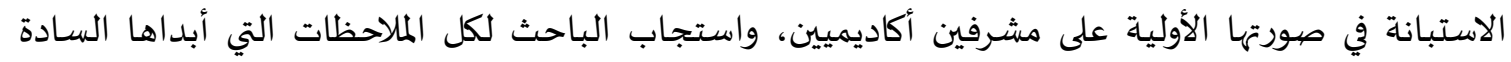

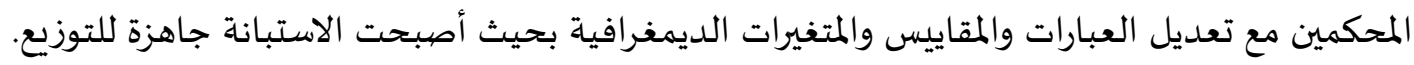

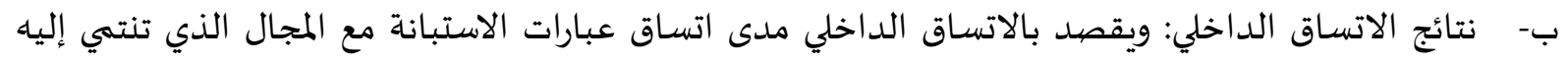

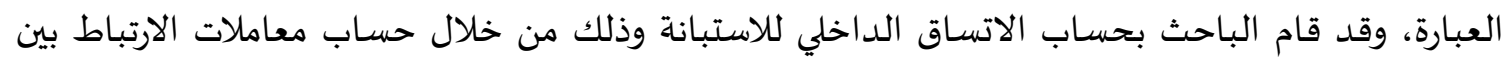

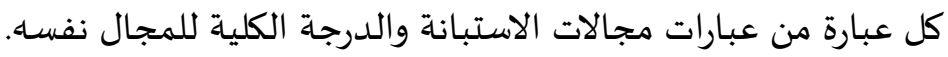

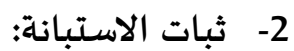

إن المقصود بثبات الاستبانة هو أنه لو تم إعادة توزيع الاستبانة لأكثر من مرة وتحت نفس الظروف الأه

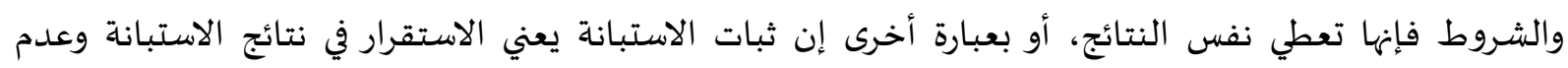

\begin{tabular}{|c|c|}
\hline معامل الفا & محاور الاستبانة \\
\hline 0.955 & التخطيط الاستراتيجي \\
\hline 0.971 & إدارة الأزمات \\
\hline 0.963 & جميع محاور الاستبانة \\
\hline
\end{tabular}

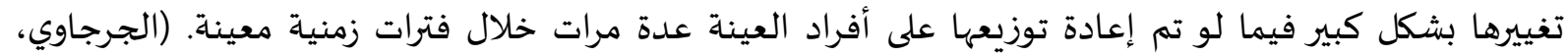

معامل ألفا كرو نباخ Cronbach's Alpha Coefficient: تم تقدير ثبات الاستبانة، وذلك باستخدام طريقة معامل ألفا كرو نباخ، والنتائج كما في الجدول الآتي:

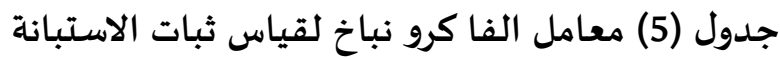

يتضح من النتائج الموضحة في الجدول (5) أن قيمة معامل ألفا كرو نباخ كانت مرتفعة لكل محور من

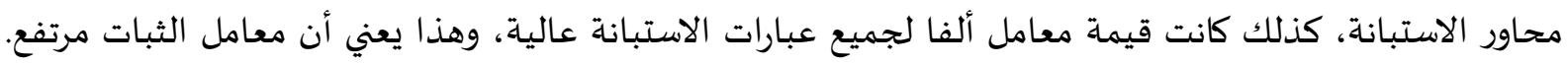
وبذلك تم التأكد من صدق وثبات استبانة الدراسة مما يجعلنا على ثقة تامة بصحة الاستبانة وصلاحيتها لتحليل

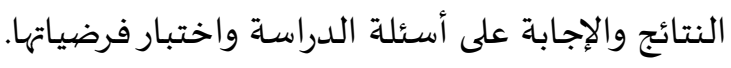


الأسـاليب الإحصيائية المستخدمة:

النسب المئوية والتكرارات والمتوسط الحسابي: يستخدم هذا الأمر بشكل أساسي لأغراض معرفة تكرار فئات

متغيرٍ ما يفيدُ الباحث في وصف عينة الدراسة المبحوثة.

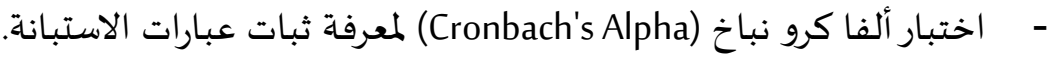

- اختبار التوزيع الطبيعي اختبار كولمجروفسيمرنوف (KOLMOGOROV-SMIRNOV) لمعرفة هل توزيع البيانات

يتبع توزيعا طبيعيا.

- معامل ارتباط سيبرمان (sperman Correlation Coefficient) لقياس درجة الارتباط: يقوم هذا الاختبار على لمانى

دراسة العلاقة بين متغيرين. وقد استخدمها الباحث لحساب الاتساق الداخلي والبنائي للاستبانة.

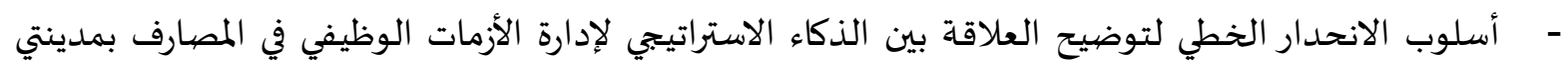

خميس مشيط وأبها وتوضيح مدى قيمة معامل الانحداروقيمة الاختبار ومعامل بيتا.

\section{5- عرض النتائج ومناقشتها.}

إجابة السؤال الأول: "هل يتّبع القطاعي المصرفي في منطقة عسير طرائق ونتائج علمية حديثة في مجال العمل

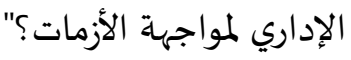

وللإجابة على هذا السؤال تم استخدام الوسط الحسابي والانحراف المعياري والوزن النسبي لأبعاد المحور

الأول من خلال تحليل الذكاء الاستراتيجي.

أولاً - تحليل الذكاء الاستراتيجي:

جدول (6) الوسط الحسابي والانحراف المعياري والوزن النسبي لأبعاد الذكاء الاستراتيجي

\begin{tabular}{|c|c|c|c|c|}
\hline 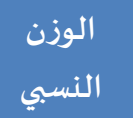 & 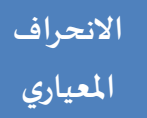 & المتوسط المسابي & 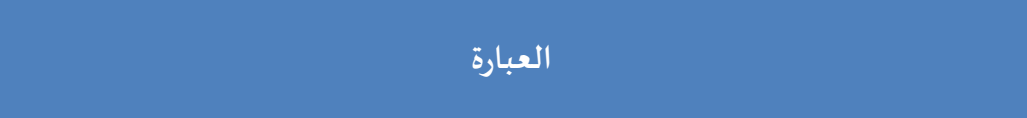 & r \\
\hline \multicolumn{5}{|c|}{ البعد الأول: الاستشراف } \\
\hline $71.98 \%$ & 1.12643 & 3.5988 & تضعع إدارة المصرف خطة استشراف للمستقبل للوصول إلى التميز في مواجهة & 1 \\
\hline $78.64 \%$ & 1.03873 & 3.9321 & تقوم إدارة المصرف باتباع طرق حديثة في تعليم واكتساب المعرفة للعاملين فهيا. & 2 \\
\hline $76.91 \%$ & 1.08506 & 3.8457 & تواكب إدارة المصرف كافة التغيرات المطروحة للوصول للتقدم في المستقبل. & 3 \\
\hline $74.75 \%$ & 98707. & 3.7377 & تبادر إدارة المصرف باستمرار في تحليل المستقبل والتنبؤ بالأحداث. & 4 \\
\hline $77.16 \%$ & 84228. & 3.8580 & تتقدم إدارة المصرفف بتوازي يتناسب مع التصهورات الحديثة المتطورة. & 5 \\
\hline $83.52 \%$ & .90231 & 4.1759 & \multicolumn{2}{|l|}{ الدرجة الكلية للبعد الأول } \\
\hline \multicolumn{5}{|c|}{ البعد الثاني: الرؤية البعا } \\
\hline $79.26 \%$ & 86836. & 3.9630 & تشتمل رؤية إدارة المصرف على كافة التطلعات المستقبلية لها. & 6 \\
\hline $81.54 \%$ & 78111. & 4.0772 & يشارك العاملون في وضيع الرؤيا الاستراتيجية في إدارة المصرف. & 7 \\
\hline $76.98 \%$ & 1.05512 & 3.8488 & تسعى إدارة المصرف للوصول للصورة الذهنية المنشودة لدى العملاء. & 8 \\
\hline $83.21 \%$ & 83953. & 4.1605 & تعمل إدارة المصرف على توحيد الجهود المتفرقة من أجل تحقيق أهدافها المنشودة & 9 \\
\hline $86.42 \%$ & 73526. & 4.3210 & تسير قرارات إدارة المصرف بنفس اتجاه الرؤية الاستراتيجية. & 10 \\
\hline $81.48 \%$ & .66151 & 4.0741 & \multicolumn{2}{|l|}{ الدرجة الكلية للبعد الثاني } \\
\hline \multicolumn{5}{|c|}{ البعد الثالث: التفكير } \\
\hline
\end{tabular}




\begin{tabular}{|c|c|c|c|c|}
\hline النسبي & الانحراف & المتوسط الحسابي & 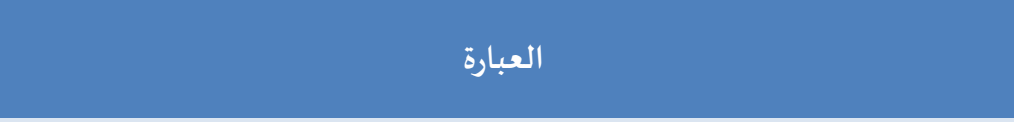 & $\hat{\imath}$ \\
\hline $\mathbf{8 6 . 9 8 \%}$ & 65267. & 4.3488 & تحلل إدارة المصرف المشكلة لمعرفة أسبابها مجتمعة لحلها بدلاً من فصلها. & 11 \\
\hline $85.00 \%$ & 75219. & 4.2500 & يساهم التفكير في رؤية البيئة المحيطة بإدارة المصرف بصهورة أكثرواقعية. & 12 \\
\hline $79.14 \%$ & 97871. & 3.9568 & تقوم إدارة المصرف باستخدام جلسـات العصف الذهني للتفكير بتطوير العاملين. & 13 \\
\hline $76.91 \%$ & 1.02036 & 3.8457 & $\begin{array}{c}\text { تستطيع إدارة المصرف جمع عناصرها لتطبيق العصف الفكري لجمع الأفكار } \\
\text { وتحليلهها. }\end{array}$ & 14 \\
\hline $76.98 \%$ & 1.01321 & 3.8488 & تتعامل إدارة المصرف مع المشكلة بشكل كلي دون تقسيمها إلى أجزاء حتى يتم حلها & 15 \\
\hline $81.00 \%$ & .69911 & 4.0500 & \multicolumn{2}{|l|}{ الدرجة الكلية للبعد الثالث } \\
\hline \multicolumn{5}{|c|}{ 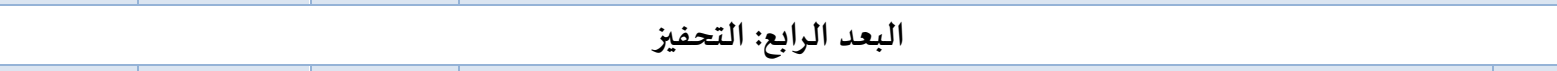 } \\
\hline $81.36 \%$ & 85207. & 4.0679 & تحث إدارة المصرف العاملين على تحمل المسؤولية والمشاركة في اتخاذ القرارات. & 16 \\
\hline $79.75 \%$ & 93098. & 3.9877 & تحفز إدارة المصرف العاملين فيه للتعامل مع أهدافها بشكل متسلسل لكي تتحقق. & 17 \\
\hline $80.93 \%$ & 86969. & 4.0463 & تشجع إدارة المصرف التفاعل المتبادل بين العاملين ليكونوا على قلب رجل واحد. & 18 \\
\hline $77.35 \%$ & 1.14747 & 3.8673 & تكافئ إدارة المصرف العاملين بحوافز مختلفة لتدعمهم لإنجاز أعمالهم. & 19 \\
\hline $79.20 \%$ & 97091. & 3.9599 & تحفز إدارة المصرف العاملين لتطبيق رؤيتها على أرض الواقع وبالشكل المحدد. & 20 \\
\hline $79.72 \%$ & .77941 & 3.9858 & \multicolumn{2}{|l|}{ 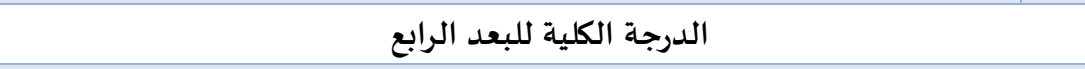 } \\
\hline \multicolumn{5}{|c|}{ 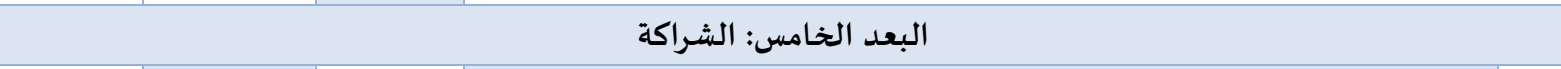 } \\
\hline $77.96 \%$ & 96957. & 3.8981 & تحافظ إدارة المصرف على استخدام أسـاليب تفيد في تحقيق الرؤية والرسالة. & 21 \\
\hline $76.91 \%$ & 1.07358 & 3.8457 & تساهم الشراكة في تحقيق التطور المستمر استراتيجياً في إدارة المصرف. & 22 \\
\hline $83.95 \%$ & 74101. & 4.1975 & تدعم الشراكة في تطوير أداء العاملين في إدارة المصرف. & 23 \\
\hline $81.79 \%$ & 86630. & 4.0895 & تعتمد إدارة المصرف على تحالفات ذات خبرات كبيرة لاتخاذ قرارات صائبة في ظلل & 24 \\
\hline $79.20 \%$ & 97726. & 3.9599 & 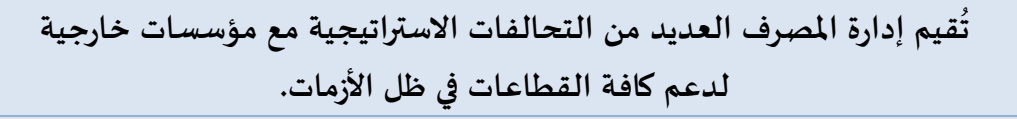 & 25 \\
\hline $79.96 \%$ & .73674 & 3.9981 & \multicolumn{2}{|l|}{ الدرجة الكلية للبعد الخامس } \\
\hline $83.80 \%$ & .66543 & 4.1901 & \multicolumn{2}{|l|}{ الدرجة الكلية لمحور أبعاد المنظمة المتعلمة } \\
\hline
\end{tabular}

أشارت النتائج إلى أن مستوى استجابات أفراد عينة الدراسة على عبارات الأبعاد الخمسة لمحور الذهاء الذهاء

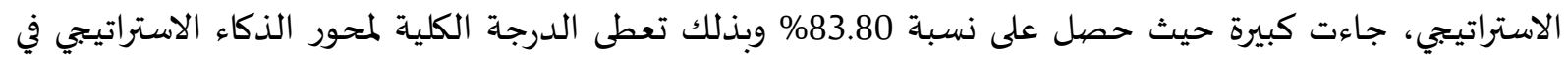
القطاع المصرفي السعودي بمنطقة عسير.

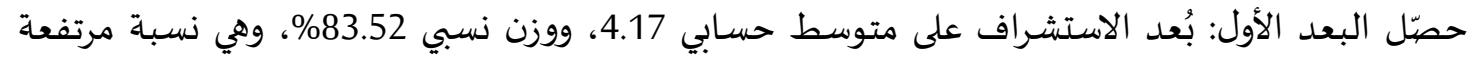

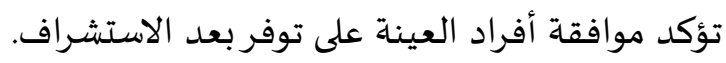

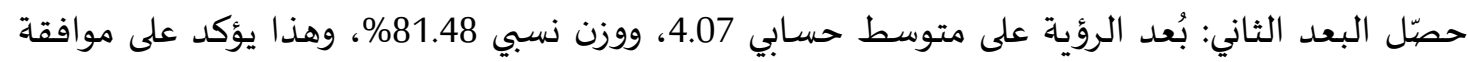

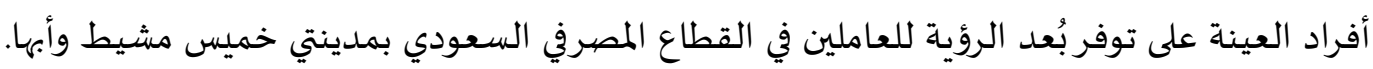

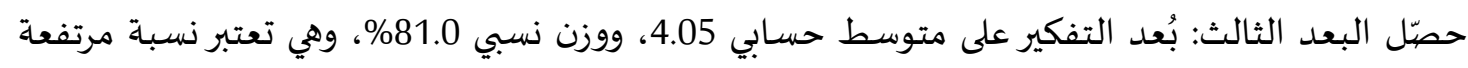

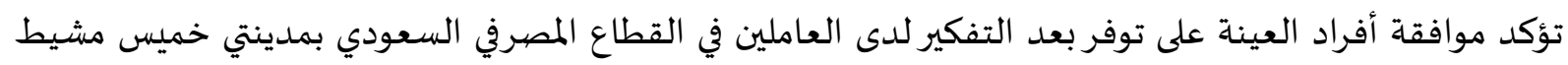
وأبها. 
حصّّل البعد الرابع: بُعد التحفيز على متوسط حسابي 3.98، ووزن نسبي 79.72\%، وهي نسبة مرتفعة تؤكد

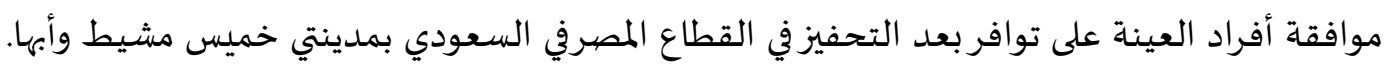

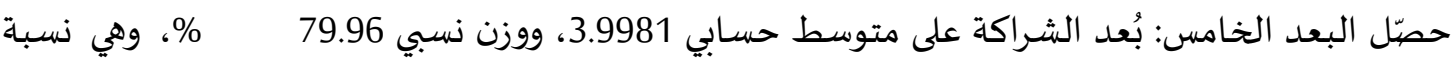
مرتفعة تؤكد موافقة أفراد العينة على توافر بُعد الشراكة. وبالتالي نقبل الفرضية الأولى التي تنص على تواصنى وجود تطبيق للذكاء الاستراتيجي في القطاع المصرفي بمنطقة

إجابة السؤال الثاني: "هل هناك تطابق حقيقي بين الخطط الاستراتيجية المُعلنة والأداء الفعلي على أرض

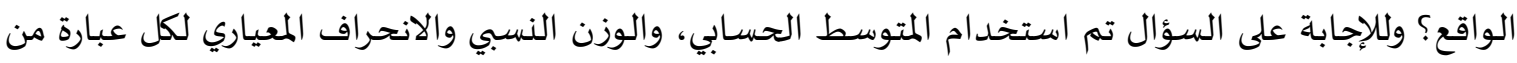

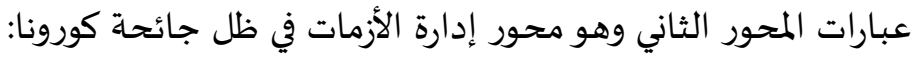

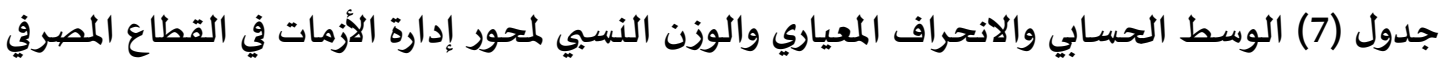
السعودي بمدينتي خميس مشيط وأبها

\begin{tabular}{|c|c|c|c|c|}
\hline 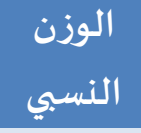 & المعياري - الانحراف & المتوسط ابطي & 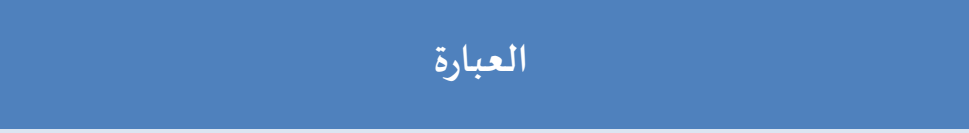 & r \\
\hline $72.96 \%$ & 1.18281 & 3.6481 & تضع إدارة المصرف خطة بديلة للعمل بها في ظل انتشار جائحة كورونا. & 1 \\
\hline $68.64 \%$ & 1.29718 & 3.4321 & توظف إدارة المصرف بوضع لجنة لإدارة أزمة كورونا ومتابعتها. & 2 \\
\hline $67.35 \%$ & 1.16355 & 3.3673 & تقوم إدارة المصرف بوضع خطة لإدارة الأزمات بكافة مراحلها القبلية & 3 \\
\hline $68.95 \%$ & 1.28592 & 3.4475 & تعمل لجنة إدارة الأزمات في المصرف على التنبؤ بالأزمات قبل حدوثها. & 4 \\
\hline $68.64 \%$ & 1.23608 & 3.4321 & تساهم لجنة إدارة الأزمات في وضع حلول خاصية بالمصرف لكيفية & 5 \\
\hline $71.36 \%$ & 1.20821 & 3.5679 & تتوافر لدى إدارة المصرف العديد من المهارات والخبرات الكافية & 6 \\
\hline $68.83 \%$ & 1.16964 & 3.4414 & اتبعت إدارة المصرف عملية التخصيص والتوزيع للمهام للخروج بأقل & 7 \\
\hline $72.84 \%$ & 1.22218 & 3.6420 & تقوم إدارة المصرف على ضبط العمل الإداري بكافة تفاصيله في ظل & 8 \\
\hline $85.56 \%$ & 84201. & 4.2778 & درست إدارة المصرف التجارب السابقة للدول الأخرى في ظل جائحة & 9 \\
\hline $78.95 \%$ & 97668. & 3.9475 & تحاول إدارة المصرف تطبيق التجارب الدولية المختلفة في مواجهة & 10 \\
\hline $73.73 \%$ & .83718 & 3.6865 & الدرجة الكلية للمحور الثاني & \\
\hline
\end{tabular}

أشارت النتائج إلى أن مستوى استجابات أفراد عينة الدراسة على عبارات محور إدارة الأزمات في ظل جائحة

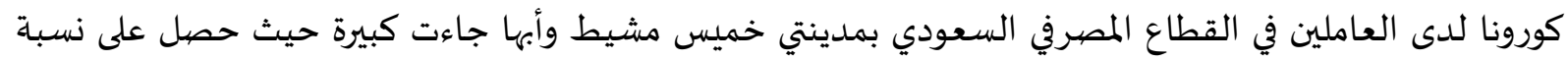

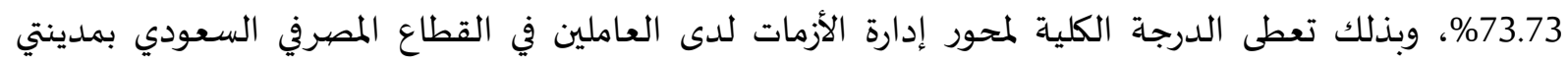


خميس مشيط وأبها. وبالتالي نقبل الفرضية الثانية وهي وجود اهتمام بالقطاع المصرفي لإدارة الأزمات بدرجة متوسطة.

إجابة السؤال الثالث: ما مدى تأثير الذكاء الاستراتيجي على إدارة الأزمات في القطاع المصرفي بمنطقة عسير؟

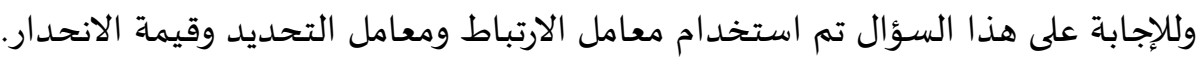

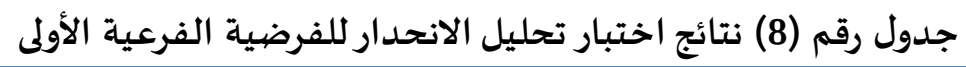

\begin{tabular}{|c|c|c|c|c|c|}
\hline مستوى الدلالة & معامل الانحدار & اختبار قيمة & معامل التحديد & $\begin{array}{c}\text { معامل } \\
\text { R الارتباط }\end{array}$ & البيان \\
\hline 0.000 & 2.130 & 3.206 & .4747 & $.689(a)$ & يوجد إدأثير للذكاء الاستراتيجي على الأزمات في القطاع المصرفي \\
\hline
\end{tabular}

يوضح الجدول السابق أن مستوى الدلالة 0.000 وهي أقل من 5\% بذلك علك نرفض الفرضية الصفرية ونقبل

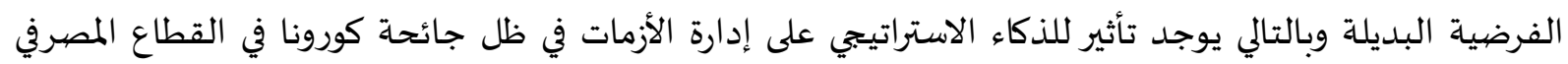

بمنطقة عسير.

\section{تحليل ومناقشّة الفرضيات:}

1- تبين أن بُعد الاستشراف يطبق بنسبة مرتفعة بلغت 83.52\%، وهي نسبة تؤكد موافقة أفراد العينة على توفر

$$
\text { بُعد الاستشراف. }
$$

2- اتضح أن نسبة تطبيق بُعد الرؤية في القطاع المصرفي بلغت 81.48\%، وهي نسبة مرتفعة تؤكد أن المصارف

$$
\text { تطبق بعد الرؤية. }
$$

3- تبين أن بُعد التفكير يطبق بنسبة 81.0\%، وهي تعتبر نسبة مرتفعة تؤكد موافقة أفراد العينة على توفر بعد

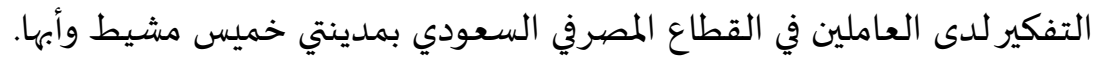
4- تبين أن بُعد التحفيز يطبق في القطاع المصرفي بنسبة 79.72\%، وهي نسبة جيدة تؤكد موافقة أفراد العينة على توافر بُعد التحفيز في القطاع المصرفي السعودي بمدينتي خميس مشيط وأبها في حين أثبتت دراسة (جعفر، تونة 2017) أن قلة تحفيز الموظفين يقلل من فعالية إدارة الأزمات. 5- اتضح أن بُعد الشراكة يطبق بنسبة جيدة بنسبة 79.96\%، وهي نسبة مرتفعة تؤكد موافقة أفراد العينة على

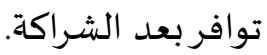

6- من خلال التحليل تبين أنه يوجد تطبيق للذكاء الاستراتيجي في القطاع المصرفي بمنطقة عسير بدرجة كبيرة جداً.

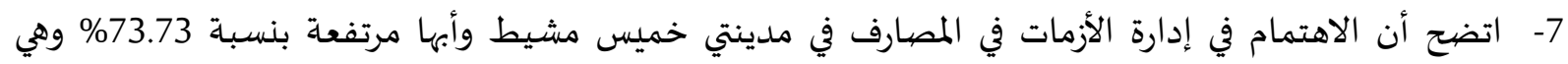

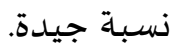

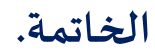

من خصائص عصرنا الحاضر ووفق مقتضيات التطور السريع والتغيرات التقنية والتقدم الآلي أن يكون

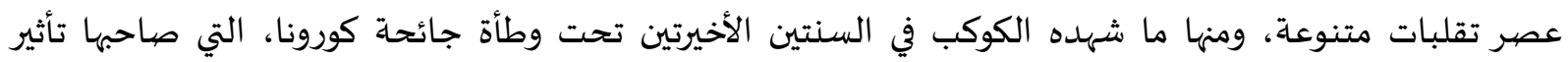
عالمي على مستويات عدة، اقتصادية واجتماعية وبيئية، فكان لزاما أن تقوم المؤسسات المالية، بكونها المؤسسات 
المتحكمة في الاقتصاد وذات الأثر المهم في ثبات ركائز أي دولة، أن تولي احتمالية المفاجئات غير المتوقعة وأن تكون على قدر استشراف المستقبل بما يحفظها من موجات وتقلبات.

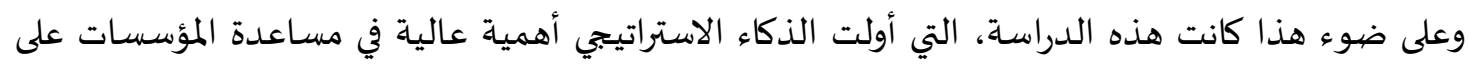

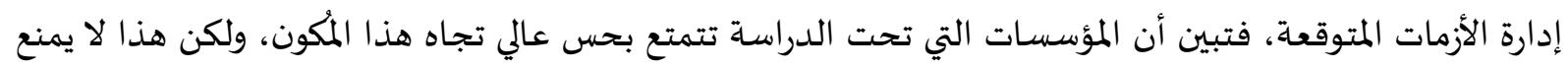

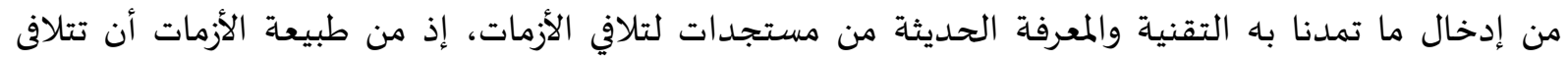

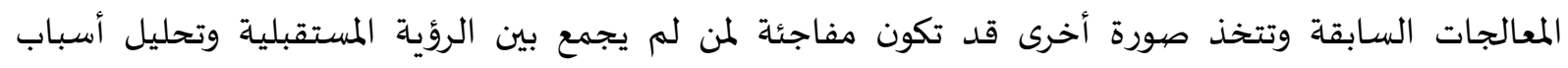

المشكلات. من هذا المنطلق توصل البحث إلى عدة نتائج نستعرضها فئها فيما يلي:

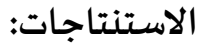

1- وجود تأثير ذو دلالة إحصائية للذكاء الاستراتيجي بأبعاده (الاستشراف، الرؤية، التحفيز، الشراكة، التفكير) على

صُناع القرار.

2- وجود توافق عالي بين الخطط الاستراتيجية في المصارف والأداء الفعلي على أرض الواقع وهذا يدل على قدرة

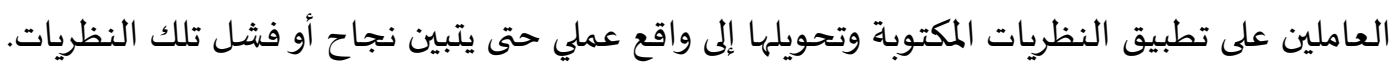

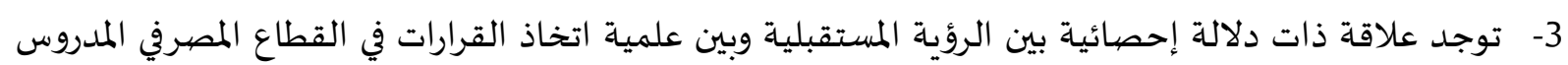

وهذا يؤكد قدرة العاملين في القطاع المصرفي المدروس على رسم خارطة مستقبلية تُمكنهم من تحديد المتغيرات

التي تطرأ خلال الأزمات.

4- ـ وجود علاقة بين تفكير العالمين في القطاع المصرفي وعملية إدارة الأزمات في ظل جائحة كورونا، وهذا يبين قدرة

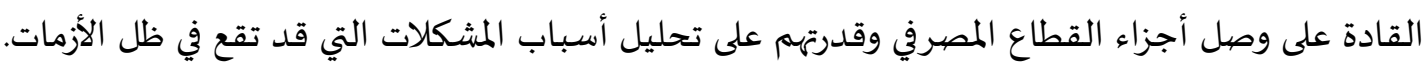

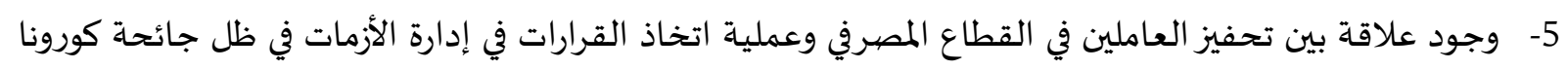

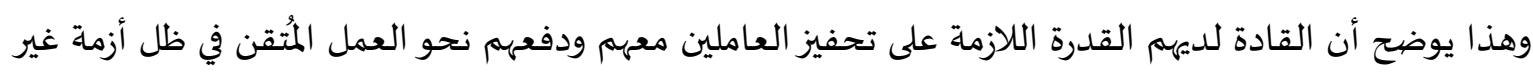

معتادة.

6- وجود علاقة بين الشراكة كأحد أبعاد الذكاء الاستراتيجي وعملية اتخاذ القرارات. وهذا يوضح مقدار الوعي عند العاملين في القطاع المصرفي بأهمية الشراكة في تحقيق أهداف المؤسسة المادية المالية.

التوصيات والمقترحات.

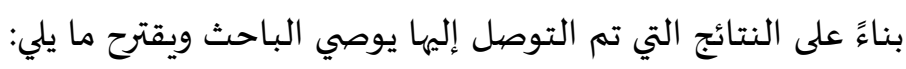

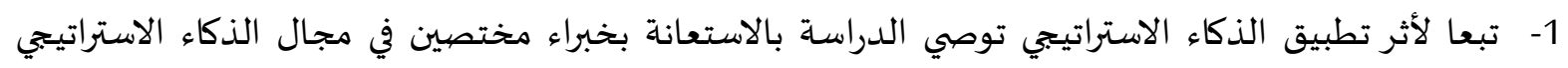
وذلك للمحافظة على قوة تأثير الأبعاد الخاصة به وتوظيفه بطرق متعددة مع احتمالية تعدد صور الأزمات

المستقبلية.

2- تحفيز العاملين في القطاع المصرفي للحصول على شهادات مهنية في الذكاء الاستراتيجي وإدارة الأزمات.

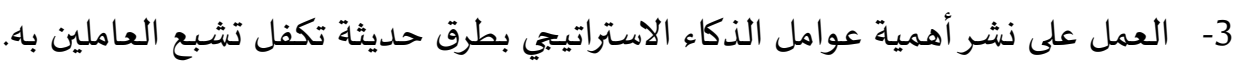

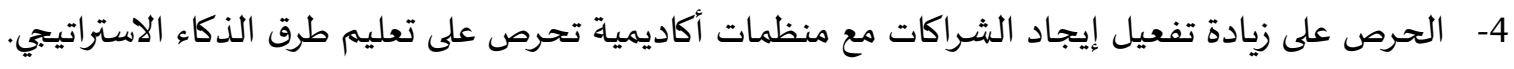

5- تفعيل الخطط المستقبلية التي تتوقع حصول أزمات مستقبلية بناء على دراسات وادئ واقعية بناءة.

6- الحرص على ادخال مستجدات في مجال تقنية المعلومات والمتمثلة في الذكاء الاصطناعي والاستفادة منهاه في

مجال الذكاء الاستراتيجي. 
7- عدم السماح بانخفاض مستوى الأداء والحرص على رفعه مع كل أزمة يمر بها القطاع المصرفي.

$$
\text { • قائمة المراجع. }
$$

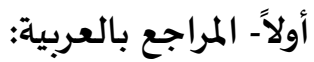

- - إبراهيم الزيات وآخرون، (2004) كتاب المعجم الوسيط، الطبعة الرابعة، مجمع اللغة العربية، مصر.

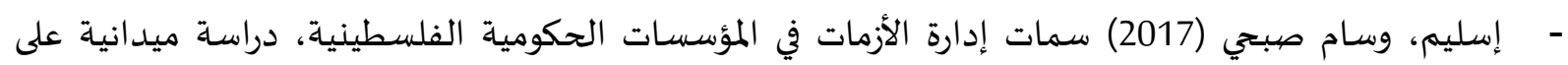
وزارة المالية في غزة (رسالة ماجستير)، الطبعة الأولى، الجامعة الإسلامية، فلسطين.

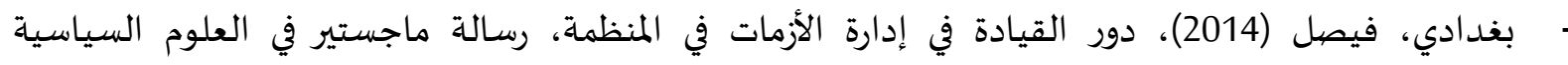
والعلاقات الدولية، الطبعة الأولى، جامعة المسيلة، الجزائر.

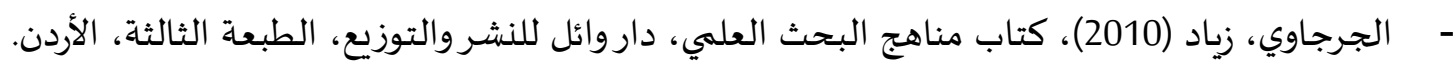

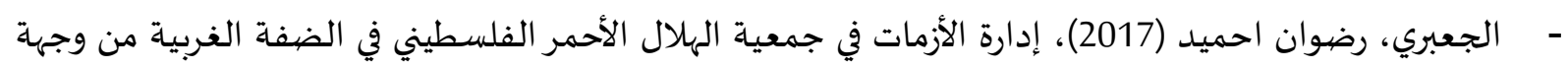

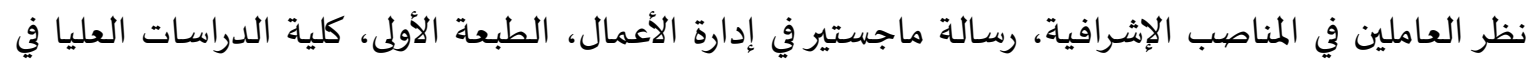
جامعة الخليل، فلسطين. جعفر، يونس (2017)، أثر التخطيط الاستراتيجي في إدارة الأزمات، دراسة تطبيقية المؤسسات العامة في منطقة

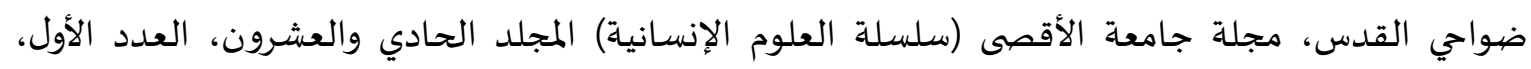
فلسطين. - الجنابي، أميرة هاتف (2018)، الإبداع الإداري وتأثيره في التطور التنظيمي، دراسة تطبيقية في شركة الوسام لمنتجات الألبان، العراق. الخفاجي، نعمة عباس؛ والبغدادي، عادل هادين (2015)، ملامح الشخصية الاستراتيجية للمدراء، منظور

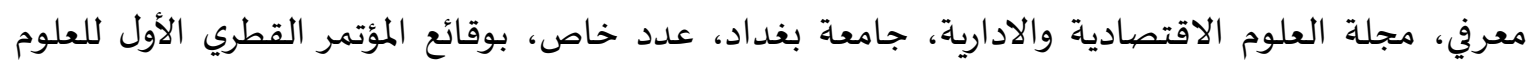
الإدارية، العراق.

- - - خير الله، جمال أنيس (2018) كتاب الإبداع الإداري، الطبعة الأولى، دار أسامة للنشروالتوزيع، الأردن.

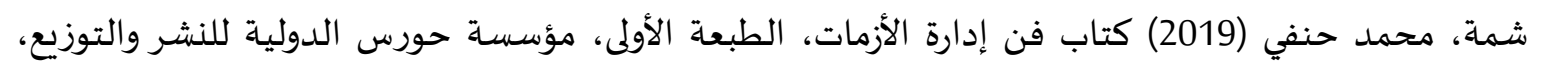
صالح، أحمد علي وآخرون (2017)، كتاب الإدارة بالذكاءات، نهج التميز الاستراتيجي والاجتماعي للمنظمات، الطبعة الأولى، داروائل للنشر، الأردن.

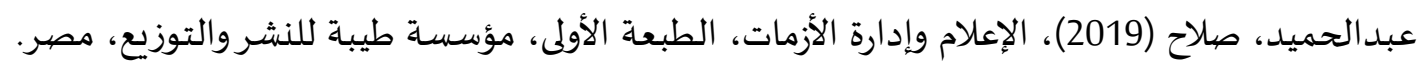

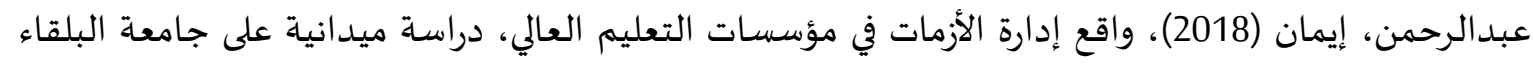
التطبيقية، جامعة البلقاء التطبيقية، الأردن. عبداللطيف، عبد اللطيف (2016)، تكنولوجيا المعلومات ودورها في التنمية الاقتصادية، بحث مقدم للمؤتمر العلمي السنوي الثاني لكلية الإدارة والعلوم الإدارية، جامعة الزيتونة الخاصية، الأردن. 
- العزاوي وبشرى هاشم محمد (2018)، أثر العلاقة بين الذكاء الاستراتيجي وقرارات عمليات الخدمة في النجاح

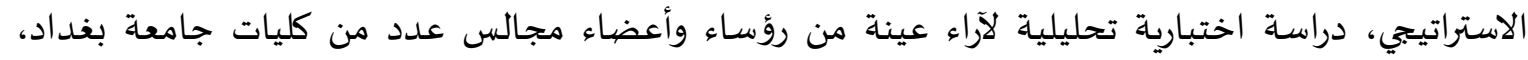

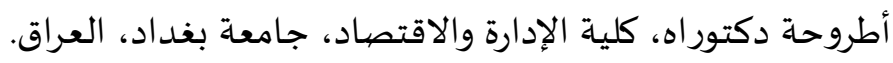

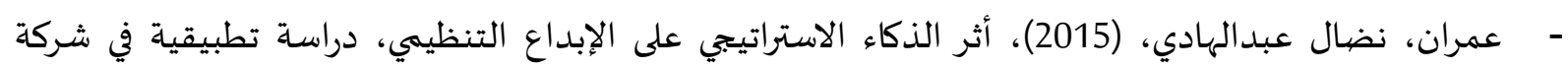
آسياسيل للاتصالات، مجلة جامعة بابل، العدد (3)، المجلد (23)، العراق.

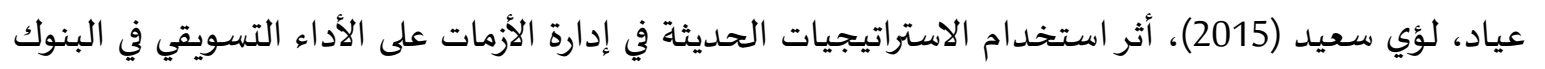
المحلية في قطاع غزة، رسالة ماجستير، الجامعاة الإسلامية، فلسطين.

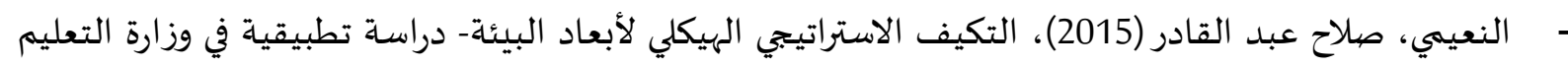

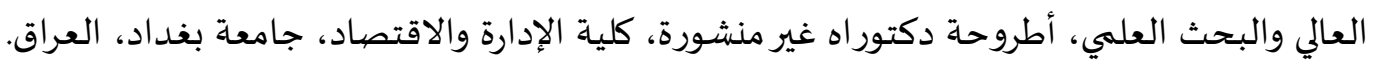

\section{ثانيًا- المراجع بالإنجليزية:}

- Kuhlmann, S. et al, (2017) , "Improving Distributed Intelligence In Complex nnovation Systems", Final Report of the Advanced Science \& Technology Policy Planning Network (ASTPP), Karlsruhe, (June), www.isi.fhg.de/, pp. (1-85).

- Parnell, J. (2015). Crisis Management and Strategic Orientation in Small and Medium- Sized Enterprises (SMEs) in Peru, Mexico, and the United States. Journal of Contingencies and Crisis Management, 23(4) , 221-234.

- Source: Tham, K. \& Kim, M., "Towards Strategic Intelligence with Anthology Based Enterprise modeling \& ABS", Proceeding of the international business \& economic research,2016:3 